\title{
ROLE OF PARP ACTIVITY IN LUNG CANCER-INDUCED CACHEXIA: EFFECTS ON MUSCLE OXIDATIVE STRESS, PROTEOLYSIS, ANABOLIC MARKERS AND PHENOTYPE
}

\begin{tabular}{|c|c|}
\hline Journal: & Journal of Cellular Physiology \\
\hline Manuscript ID & JCP-16-0172.R2 \\
\hline Wiley - Manuscript type: & Original Research Article \\
\hline Date Submitted by the Author: & $\mathrm{n} / \mathrm{a}$ \\
\hline Complete List of Authors: & $\begin{array}{l}\text { Chacon-Cabrera, Alba; IMIM-Hospital del Mar, UPF, PRBB, CIBERES, } \\
\text { Pulmonology-URMAR } \\
\text { Mateu-Jimenez, Merce; IMIM-Hospital del Mar, UPF, PRBB, CIBERES, } \\
\text { Pulmonology-URMAR } \\
\text { Langohr, Klaus; Department of Statistics and Operations Research, } \\
\text { Universitat Politècnica de Barcelona/ Barcelonatech, Barcelona Spain, } \\
\text { Department of Statistics and Operations Research } \\
\text { Fermoselle, Clara; IMIM-Hospital del Mar, UPF, PRBB, CIBERES, } \\
\text { Pulmonology-URMAR } \\
\text { Garcia-Arumi, Elena; Hospital Universitari Vall d\'Hebron Institut de } \\
\text { Recerca (VHIR), Universitat Autònoma de Barcelona, CIBERER, Unitat de } \\
\text { Patologia Neuromuscular i Mitocondrial } \\
\text { Andreu, Antoni; Hospital Universitari Vall d\'Hebron Institut de Recerca } \\
\text { (VHIR), Universitat Autònoma de Barcelona, CIBERER, Unitat de Patologia } \\
\text { Neuromuscular i Mitocondrial } \\
\text { Yelamos, Jose; Hospital del Mar Medical Research Institute (IMIM)-Hospital } \\
\text { del Mar, CIBERehd, Cancer Research Program-Immunology } \\
\text { Barreiro, Esther; IMIM-Hospital del Mar, Health and Experimental Sciences } \\
\text { Department (CEXS), Universitat Pompeu Fabra (UPF), Barcelona } \\
\text { Biomedical Research Park (PRBB), CIBERES, Pulmonology Department- } \\
\text { Muscle Wasting and Cachexia in Chronic Respiratory Diseases and Lung } \\
\text { Cancer }\end{array}$ \\
\hline Key Words: & $\begin{array}{l}\text { - cancer-induced cachexia, - muscle atrophy and myosin loss, - Parp-1-/- } \\
\text { and Parp-2-/- mice, PARP activity, muscle anabolism and catabolism and } \\
\text { mitochondrial content }\end{array}$ \\
\hline
\end{tabular}

\section{SCHOLARONE \\ Manuscripts}


ROLE OF PARP ACTIVITY IN LUNG CANCER-INDUCED CACHEXIA: EFFECTS ON MUSCLE OXIDATIVE STRESS, PROTEOLYSIS, ANABOLIC MARKERS AND PHENOTYPE

Alba Chacon-Cabrera ${ }^{1,2}$, Mercè Mateu-Jimenez ${ }^{1,2}$, Klaus Langohr $^{3,4}$, Clara Fermoselle ${ }^{1}$, Elena García-Arumí, ${ }^{5,6}$, Antoni L. Andreu ${ }^{5,6}$, Jose Yelamos ${ }^{7,8}$, and Esther Barreiro ${ }^{1,2}$

${ }^{1}$ Pulmonology Department-Lung Cancer and Muscle Research group, IMIM-Hospital del Mar, Health and Experimental Sciences Department (CEXS), Universitat Pompeu Fabra (UPF), Barcelona Biomedical Research Park (PRBB), C/ Dr. Aiguader, 88, Barcelona.

${ }^{2}$ Centro de Investigación en Red de Enfermedades Respiratorias (CIBERES), Instituto de Salud Carlos III (ISCIII), Barcelona, Spain.

${ }^{3}$ Integrative Pharmacology and Systems Neuroscience Research Group, Neurosciences Research Program, Hospital del Mal Medical Research Institute (IMIM), Barcelona, Spain

${ }^{4}$ Department of Statistics and Operations Research, Universitat Politècnica de Barcelonal Barcelonatech, Barcelona Spain

${ }^{5}$ Unitat de Patologia Neuromuscular i Mitocondrial, Hospital Universitari Vall d'Hebron Institut de Recerca (VHIR), Universitat Autònoma de Barcelona.

${ }^{6}$ Centro de Investigación Biomédica en Red de Enfermedades Raras (CIBERER), ISCIII, Barcelona, Spain.

${ }^{7}$ Cancer Research Program-Immunology, Hospital del Mar Medical Research Institute (IMIM)Hospital del Mar, Barcelona, Spain

${ }^{8}$ Centro de Investigación en Red de Enfermedades Hepáticas y Digestivas (CIBERehd), Instituto de Salud Carlos III (ISCIII), Barcelona, Spain.

Corresponding author: Dr. Esther Barreiro, Pulmonology Department, IMIM-Hospital del Mar, PRBB, C/ Dr. Aiguader, 88, Barcelona, E-08003 Spain, Telephone: (+34) 93316 0385, Fax: (+34) 933160410 , e-mail: ebarreiro@imim.es.

Running head: Muscle biology in cancer-induced cachexia of PARP-1 and -2 deficient mice 


\section{Word count: 6,547}

KEY WORDS: cancer-induced cachexia; PARP activity; muscle anabolism and catabolism and mitochondrial content; muscle atrophy and myosin loss; Parp- $1^{-1-}$ and Parp $-2^{-1-}$ mice

\section{Number of text figures: 8}

\section{Number of tables: 2}

Grant information: The study has been funded by Instituto de Salud Carlos-III, contract grant numbers, CIBERES, FIS 11/02029, FIS 14/00713, Catalan Foundation of Pulmonology (FUCAP), contract grant numbers, FUCAP 2011, FUCAP 2012, and FUCAP 2016, Spanish Respiratory Society (SEPAR) 2016, and Fundació La Marató de TV3, contract grant number 2013-4130.

John Wiley \& Sons, Inc. 


\begin{abstract}
Strategies to treat cachexia are still at its infancy. Enhanced muscle protein breakdown and ubiquitinproteasome system are common features of cachexia associated with chronic conditions including lung cancer (LC). Poly(ADP-ribose) polymerases (PARP), which play a major role in chromatin structure regulation, also underlie maintenance of muscle metabolism and body composition. We hypothesized that protein catabolism, proteolytic markers, muscle fiber phenotype, and muscle anabolism may improve in respiratory and limb muscles of LC-cachectic Parp-1-deficient (Parp- $1^{-/}$) and Parp- $2^{-/-}$mice. In diaphragm and gastrocnemius of LC (LP07 adenocarcinoma) bearing mice (wild type, Parp- $1^{-/-}$and Parp-2 $2^{-/}$), PARP activity (ADP-ribose polymers, pADPr), redox balance, muscle fiber phenotype, apoptotic nuclei, tyrosine release, protein ubiquitination, muscle-specific E3
\end{abstract} ligases, NFkB signaling pathway, markers of muscle anabolism (Akt, mTOR, p70S6K, and mitochondrial DNA) were evaluated along with body and muscle weights and limb muscle force. Compared to wild type cachectic animals, in both respiratory and limb muscles of Parp- $1^{-/-}$and Parp$2^{-/-}$cachectic mice: cancer induced-muscle wasting characterized by increased PARP activity, protein oxidation, tyrosine release, and ubiquitin-proteasome system (total protein ubiquitination, atrogin-1, and 20S proteasome C8 subunit) were blunted, the reduction in contractile myosin and atrophy of the fibers was attenuated, while no effects were seen in other structural features (inflammatory cells, internal or apoptotic nuclei), and markers of muscle anabolism partly improved. Activation of either PARP-1 or -2 is likely to play a role in muscle protein catabolism via oxidative stress, NF-kB signaling, and enhanced proteasomal degradation in cancer-induced cachexia. Therapeutic potential of PARP activity inhibition deserves attention.

Word count: 250 


\section{Introduction}

In advanced stages of respiratory and cardiac diseases and malignancies, the prevalence of muscle wasting and cachexia is very high (von and Anker, 2010;Diaz et al, 2014;Evans et al, 2008; Fearon et al, 2011;Leiro-Fernandez et al, 2014;Sanchez-Salcedo et al, 2015;Sanchez, 2015;Muscaritoli et al, 2006). Muscle mass loss and dysfunction have a great impact on the patients' quality of life as they severely compromise their exercise tolerance and daily-life activities. Additionally, muscle wasting and weakness were also shown to negatively influence disease prognosis and survival (Alvarez et al, 2016; Barreiro, 2017;Evans et al, 2008;Fearon et al, 2011;Muscaritoli et al, 2006;Penalver Cuesta et al, 2015;Sanchez, 2015;Sebio et al, 2015;von and Anker, 2010).

Despite that growing evidence has shown that mechanisms such as oxidative stress, systemic inflammation, ubiquitin-proteasome system, epigenetic modifications, metabolic derangements (Chacon-Cabrera et al, 2014;Fermoselle et al, 2011;Fermoselle et al, 2012;Puig-Vilanova et al, 2014;Fermoselle et al, 2013; Chacon-Cabrera et al, 2015), and myostatin (Fermoselle et al, 2011; Whittemore et al, 2003; Zhou et al, 2010) are involved in muscle wasting and cachexia, the contribution of other pathways that could have potential therapeutic implications remain to be fully identified. In this regard, it has been recently demonstrated (Chacon-Cabrera et al, 2014;Fermoselle et al, 2013; Chacon-Cabrera et al, 2015) that attenuation of mitogen-activated protein kinases

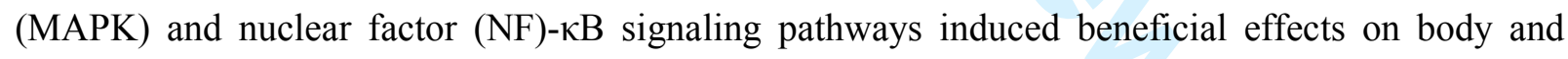
muscle weight loss and mitochondrial function in cancer-induced cachectic mice through the action of a cascade of molecular events.

Poly(adenosine diphosphate-ribose) polymerases (PARPs) consist of a family of proteins that catalytically cleave $\beta$-nicotinamide adenine dinucleotide $\left(\beta-\mathrm{NAD}^{+}\right)$into nicotinamide and ADPribose and transfer the ADP-ribose moiety to acceptor residues of target proteins (Yelamos et al, 2011). PARPs are involved in different biological functions such as maintaining genomic integrity, transcription, angiogenesis, cell death in oxidative stress-related pathologies, and metabolic and 
immune regulation (Burkle and Virag, 2013;Yelamos et al, 2011). Overactivation of PARP, which may occur as a result of increased oxidant production, exerts deleterious effects on tissues mainly by depletion of intracellular NAD+ and ATP stores that lead to cell dysfunction and death (Ha and Snyder, 1999). Importantly, this mechanism of cell destruction participates in the etiology of conditions characterized by severe muscle wasting, such as acute lung and renal injuries (Kiefmann et al, 2004;Vaschetto et al, 2008;Zheng et al, 2005) and sepsis (Jagtap et al, 2002). On the other hand, PARP-1 and PARP-2 inhibition was also shown to promote oxidative metabolism and increased energy expenditure in skeletal muscles in other studies (Bai et al, 2011b;Bai et al, 2011a) and to attenuate muscle mass loss in cancer cachectic mice through epigenetic regulation (ChaconCabrera et al, 2015). Whether inhibition of either PARP-1 or PARP-2 activities may mitigate muscle mass loss through attenuation of proteolysis and its upstream signaling pathways in models of cancer-induced cachexia remains to be fully understood. Elucidation of the biological mechanisms whereby PARP activity inhibition attenuates muscle mass loss may have potential therapeutic implications in the management of patients with cachexia as pharmacological inhibitors are currently available for the treatment of cancer. On this basis, we hypothesized that specific genetic deletion of Parp-1 and -2 in mice bearing a lung adenocarcinoma may mitigate increased muscle oxidative stress, protein breakdown and expression of proteolytic pathways, along with an improvement in the loss of contractile proteins and atrophy, and in anabolic markers. Moreover, as most of the studies conducted so far have focused on the assessment of the peripheral muscles, especially in patients, the analysis of the diaphragm muscle, which must remain continuously active, has also been included in the current investigation in order to compare potential differences in the target markers between these two muscles. This approach enabled us to analyze whether the activity of the muscle may influence the effects of PARP in cancer cachectic muscles.

Accordingly, the following objectives were established to be analyzed in the diaphragm and 
gastrocnemius muscles of Parp $-1^{-/-}$and Parp $-2^{-/-}$mice exposed to lung cancer (LC) cachexia for one month: 1) to explore levels of redox balance, protein degradation, markers of ubiquitin-proteasome pathway, contractile proteins, and muscle anabolism including mitochondrial content and 2) to evaluate muscle structural abnormalities and phenotype, and the rate of apoptotic nuclei. Finally, in order to characterize and validate the reproducibility of the model of LC-induced cachexia as compared to previously published studies, body and muscle weights, muscle structure and limb muscle strength were also measured again in all the mice used for the purpose of the current investigation. In order to ensure PARP activity inhibition, its levels were also quantified in the target muscles of all the study animals.

\section{Materials and Methods}

(See additional information on all the methodologies in the online supplementary material).

\section{Animal model}

Tumor. LP07 is a cell line derived from the transplantable P07 lung tumor that appeared spontaneously in the lung of a BALB/c mouse (Diament et al, 1998). One month after cellular inoculation, all animals developed lung metastasis, spleen enlargement, and severe cachexia without affecting any other organs (Chacon-Cabrera et al, 2014; Chacon-Cabrera et al, 2015).

Mice. BALB/c female mice (ten weeks old) were obtained from Harlan Interfauna Ibérica SL (Barcelona, Spain). Parp- $1^{-/-}$and Parp- $2^{-/-}$female mice (strain 129/Sv x C57BL/6), kindly provided by Dr. de Murcia (de Murcia et al, 1997) (Strasbourg, France), were backcrossed on BALB/c background for twelve generations. Genotyping was performed by PCR analysis using tail DNA as previously described (Corral et al, 2005). Following the principal of the 3Rs (replacement, reduction and refine) in order to reduce the number of mice used as much as possible, Parp- $1^{-1-}$ and Parp- $2^{-1}$ knockout animals were also used in another study with the aim to explore epigenetic regulation of muscle wasting (Chacon-Cabrera et al, 2015). 
Experimental design and Ethics. In all experimental groups (except for control rodents), LP07 viable cells $\left(4 \times 10^{5}\right)$ resuspended in $0.2 \mathrm{~mL}$ minimal essential media (MEM) were subcutaneously inoculated in the left flank of female BALB/c mice on day 1 and were studied for a period of one month. Fifty-eight mice were used in the study, which were further subdivided into the following groups: 1) control wild type ( $\mathrm{N}=12)$, inoculation of $0.2 \mathrm{~mL}$ MEM; 2) LC-cachexia wild type group $(\mathrm{N}=14)$, inoculation of LP07 cells in $0.2 \mathrm{~mL}$ MEM; 3$)$ control Parp- ${ }^{-1 /}(\mathrm{N}=8)$, inoculation of $0.2 \mathrm{~mL}$ MEM; 4) LC-cachectic Parp- $1^{-/-}$mice ( $\left.\mathrm{N}=12\right)$, inoculation of LP07 cells in $0.2 \mathrm{~mL}$ MEM; 5) control Parp- $2^{-/-}(\mathrm{N}=6)$, inoculation of $0.2 \mathrm{~mL}$ MEM; and 6) LC-cachectic Parp- $2^{-/-}$mice $(\mathrm{N}=6)$, inoculation of LP07 cells in $0.2 \mathrm{~mL}$ MEM. This controlled study was designed in accordance with the ethical standards on animal experimentation (EU 2010/63 CEE, Real Decreto 53/2013 BOE 34, Spain) at PRBB and the Helsinki convention for the use and care of animals. Ethical approval was obtained by the Animal Research Committee (Animal welfare department, Catalonia, EBP-09-1228).

\section{In vivo measurements in the mice}

In all the study animals, body weight and food intake were measured every day during the entire duration of the study. The function of the peripheral muscles was also measured in vivo in all the study animals. Specifically, limb force was determined using a specific grip strength meter for rodents on days 0 and 30 in all animals as previously shown in published studies (Barreiro et al, 2010a;Barreiro et al, 2016;Carter et al, 2004;Chacon-Cabrera et al, 2014;Chacon-Cabrera et al, 2015;Fermoselle et al, 2013;Xu et al, 2008) and video-clips (Chacon-Cabrera et al, 2016b;ChaconCabrera et al, 2016a). In all mice, the four limbs equally contributed to the maneuver of grip strength (Fig. E1). Control animals were paired-fed according to the amount of food eaten by the cancer cachectic rodents $(3 g / 24 h)$. Body weight and grip strength gain variables were calculated as the percentage of the measurements performed at the end of the study period (30 days) with respect to the same measurements obtained at baseline (day 0). In all the animals, body weight and limb strength gains were calculated as follows: (final body weight on day 30 - initial body weight on day 
0)/ initial body weight on day $0 \times 100$, and (grip strength on day 30-grip strength on day 0)/ grip strength on day $0 \mathrm{x} 100)$, respectively.

\section{Sacrifice and sample collection}

Mice from all experimental groups were always sacrificed on day 30 post-inoculation of LP07 cells or MEM (control animals), and diaphragm and gastrocnemius muscles (right hindlimb) were subsequently obtained. In all mice, the weight of each muscle was determined using a high-precision scale immediately after having been excised from the animals. LC-cachectic mice were macroscopically of smaller size than healthy control rodents (Chacon-Cabrera et al, 2014;ChaconCabrera et al, 2015). Frozen tissues were used for immunoblotting and real-time polymerase chain reaction assay (qRT-PCR) techniques, while paraffin-embedded tissues were used for the assessment of muscle structure abnormalities and fiber type morphometry.

\section{Biological analyses}

PARP activity. In the current study, ADP-ribose polymers (pADPr) levels were identified in the muscle nuclei of both diaphragm and gastrocnemius as a marker of PARP enzyme activity following previous methodologies (Figs. E2A and E2B) (Lai et al, 2011).

Muscle DNA isolation. Total DNA, including mitochondrial and nuclear DNA, was isolated from diaphragm and gastrocnemius muscles of all mouse experimental groups using QIAmp DNA Mini Kit (QiAgen, GmbH, Germany) (Andreu et al, 2009), following the manufacturer's protocol of DNA purification from tissues, and without the use of RNase A. Total DNA concentrations obtained from muscles were quantified using a spectrophotometer (NanoDrop, Thermo Scientific, Wilmington, Delaware, USA).

Absolute quantification of DNAs. Mitochondrial DNA (mtDNA) copy number was estimated through the quantification of the mtDNA to nuclear DNA (nDNA) ratio (mtDNA/nDNA) by real-time PCR (Andreu et al, 2009;McDermott-Roe et al, 2011).

Immunoblotting of $1 D$ electrophoresis. Protein levels of the different molecular markers analyzed in 
the study were explored by means of immunoblotting procedures as previously described (ChaconCabrera et al, 2014;Salazar-Degracia et al, 2016). Glyceraldehyde-3-phosphate dehydrogenase (GAPDH) was used as the loading control for all the immunoblots as shown in the corresponding figures.

Protein catabolism. Protein degradation was explored on the basis of the rate of production of free tyrosine from muscle proteins as previously described (Chacon-Cabrera et al, 2014).

Muscle fiber counts and morphometry. On 3-micrometer muscle paraffin-embedded sections from diaphragms and gastrocnemius muscles of all study groups, MyHC-I and -II isoforms were identified using specific antibodies (Chacon-Cabrera et al, 2014).

Muscle structure abnormalities. The area fraction of normal and abnormal muscle was evaluated on twenty 3-micrometer paraffin-embedded sections of the diaphragm and gastrocnemius of all study groups muscles following previously published methodologies (Chacon-Cabrera et al, 2014) (Fig. $\mathrm{E} 2 \mathrm{C})$

Terminal deoxynucleotidyl transferase-mediated dUTP nick-end labeling (TUNEL) assay. In muscle paraffin-embedded sections, apoptotic nuclei were identified using the TUNEL assay (ChaconCabrera et al, 2014;Salazar-Degracia et al, 2016).

\section{Statistical Analysis}

Normality of the study variables was checked using the Shapiro-Wilk test. The mean and the standard deviation were used for the descriptive analysis of the numeric variables of interest, whereas for the graphical representation of the corresponding variables the parameters mean together with the corresponding $95 \%$ confidence interval were chosen. Therefore, descriptive analyses of the target variables demonstrating the validity and reproducibility of the animal experimental model are represented as mean and standard deviation in both Tables 1 and 2 and Fig. 1. The molecular results, which are all represented in graphs, are expressed as the mean in each study group together with the corresponding 95\% confidence interval. In addition, for each variable, analysis of variance 
(ANOVA) models that included genotype, cancer, and the interaction of both were fitted. All

hypotheses of interest were tested in the framework of these models: Wild type mice with and without cancer-induced cachexia were compared. Whenever, the difference was statistically significant, cancer-cachectic and control mice were also compared in both Parp-1-/- and Parp-2-/groups of mice. The corresponding significance levels were adjusted using the Dunnett's test to correct for multiple comparisons. All the statistical analyses were carried out using the statistical software R, version 3.3.1 (Vienna, Austria; http://www.r-project.org/). In particular, the contributed "Package multcomp" (Hothorn et al, 2008) was used to accomplish the multiple comparisons. Statistical significance was set at 0.05 .

The sample size chosen was based on previous studies (Chacon-Cabrera et al, 2014;ChaconCabrera et al, 2015;Fermoselle et al, 2011), where very similar approaches were employed. In addition, statistical power was calculated using specific software (StudySize 2.0, CreoStat HB, Frolunda, Sweden). Body weight gain was selected as the target variable to estimate the statistical power in the study. On the basis of a standard power statistics established at a minimum of $80 \%$ and assuming an alpha error of 0.05 , the former parameter was sufficiently high to detect a minimum difference of 1.2 points between groups in the sample size (minimum of $\mathrm{N}=6 /$ group) and standard deviation.

\section{Results}

\section{Validation and reproducibility of the experimental model}

LC-induced cachexia. Figure $1 \mathrm{~A}$ illustrates the curves of body weight progression in the mice of all the experimental groups during the 30-day study period. As shown in Figure 1A and Table 1, at the end of the study period (day 30), cachectic wild type mice exhibited a significant reduction in body weight gain compared to their respective controls. The weights of diaphragm and gastrocnemius muscles and limb strength gain were significantly reduced in cachectic wild type mice (Table 1). 
1

2

3

4

5

6

7

8

9

Importantly, in Parp- $1^{-/}$mice, a statistically significant reduction in these parameters was also observed, but to a much lesser extent than that seen in wild type animals (Table 1). In cachectic Parp- $2^{-/}$mice, no significant differences were observed in body and muscle weights or limb strength between cachectic and non-cachectic mice (Table 1).

The expression of PARP-1 and PARP-2 was confirmed in the subcutaneous tumors of the wild type and both groups of knockout mice, as previously reported (Chacon-Cabrera et al, 2015;MateuJimenez et al, 2016). Compared to cachectic wild type animals, the weights of the subcutaneous tumors were reduced in both Parp- $-^{-/}$and Parp- $2^{-/}$LC-cachectic mice (Table 1).

Effects of Parp deletion on non-cachectic control animals. As illustrated in Table 1, non-cachectic knockout animals (Parp- $1^{-/-}$and Parp- $2^{-1}$ ) exhibited a reduction in the weights of their muscles (diaphragm and gastrocnemius) compared to wild type non-tumor animals. In the same transgenic mice at the end of the study period, no significant differences were observed in baseline body weight or the variables limb muscle strength and body weight gain compared to non-tumor wild type animals (Table 1 and Fig. 1A).

\section{PARP activity in muscles of wild type and Parp-1-/- and Parp-2 -/- mice}

LC-induced cachexia. PARP activity as measured by the number of pADPr-positively stained nuclei was significantly increased in both diaphragm and gastrocnemius of cachectic wild type mice compared to control animals (Figs. 1B, 1C, E2A, and E2B). No significant differences were seen in pADPr-positively stained nuclei counts in the study muscles between cachectic and non-cachectic mice among the two groups of knockout animals (Figs. 1B, 1C, E2A and E2B). Effects of Parp deletion on non-cachectic control animals. PARP activity was significantly lower in diaphragm and gastrocnemius of both Parp- $1^{-1 /}$ and Parp- $2^{-1 /}$ control mice than in wild type animals (Figs. 1B, 1C, E2A and E2B).

Deletions of PARP-1 and -2 mitigate increased oxidative stress 
and gastrocnemius muscles of cachectic wild type mice compared to their respective non-cachectic controls (Figs. 2A, 2B, E3A, and E3B). Diaphragm and gastrocnemius protein carbonylation levels did not differ between cachectic and non-cachectic mice in any group of knockout animals (Figs. 2A, 2B, E3A, and E3B). Protein levels of SOD2 were significantly lower in both diaphragm and gastrocnemius muscles of cachectic wild type mice than in non-tumor control animals (Figs. 2C, 2D, E3C, and E3D). No significant differences were found in muscle SOD2 protein levels between cachectic and non-cachectic mice in any of the knockout groups (Figs. 2C, 2D, E3C, and E3D). Diaphragm or gastrocnemius levels of SOD1 did not significantly differ between cachectic and noncachectic mice among the study groups (Figs. 2E, 2F, E3E, and E3F). Among each of the cachectic groups of mice, no significant correlations were found between markers of oxidative stress and other biological or physiological parameters.

Effects of Parp deletion on non-cachectic control animals. No significant differences were seen in total protein carbonylation, SOD2, or SOD1 levels between non-cachectic knockout mice and the non-cachectic wild type animals (Figs. 2A-2F, and E3A-E3F).

\section{Deletions of PARP-1 and -2 prevent the expression of proteolytic markers in cachectic muscles}

$L C$-induced cachexia. Protein degradation, as measured by the release of the amino acid tyrosine, was significantly increased in both diaphragm and gastrocnemius muscles of cachectic wild type mice compared to non-cachectic controls (Figs. 3A and 3B). Parp- $1^{-/-}$and Parp- $2^{-/-}$cancer-cachectic animals did not show any significant difference in protein degradation levels compared to their respective non-cachectic controls in any of the study muscles (Figs. 3A and 3B). Total protein ubiquitination and protein content of 20S proteasome subunit C8 were increased in both respiratory and limb muscles of cachectic wild type mice compared to non-cachectic controls (Figs. 4A-4D and E4A, E4B, E5A, and E5B). The levels of these proteolytic markers did not differ between any of the cachectic knockout groups of mice and their respective non-cachectic controls (Figs. 4A-4D and E4A, E4B, E5A, and E5B). Protein levels of E3 ligases TRIM32 and MURF-1 did not differ in 
either respiratory or limb muscles between cachectic and non-cachectic mice of any study group (Figs. 5A-5D, and E6A, E6B, E7A, and E7B). However, atrogin-1 content was significantly greater in both muscles of cachectic wild type rodents compared to protein levels in non-cachectic controls mice, and its levels did not significantly differ in these study muscles between cachectic and noncachectic knockout animals (Figs. 5E, 5F, E8A, and E8B).

Effects of Parp deletion on non-cachectic control animals. Tyrosine release levels were significantly greater in the diaphragm and gastrocnemius muscles of non-cachectic Parp- $1^{-1-}$ mice than in wild type animals, while no differences were seen between non-tumor Parp- $2^{-1-}$ mice and the wild type controls (Figs. 3A and 3B). Total protein ubiquitination, 20S proteasome subunit C8 levels, TRIM32, MURF-1 and atrogin-1 levels did not differ in diaphragm or gastrocnemius muscles between Parp- $1^{-/-}$or Parp- $2^{-/-}$non-cachectic controls and non-cachectic wild type rodents (Figs. 4A$5 \mathrm{~F}$ and $\mathrm{E} 4 \mathrm{~A}-\mathrm{E} 8 \mathrm{~B})$.

Deletions of PARP-1 and -2 attenuate the expression of atrophy signaling pathways in muscles LC-induced cachexia. Relative activated NF-kB p50 and NF-kB p65 levels were increased in the diaphragm and gastrocnemius muscles of cachectic wild type mice compared to their non-tumor controls, whereas no significant differences were observed in the same muscles between any of the cachectic knockout mice and their respective non-tumor controls (Figs. 6A-6D, E9A, E9B, E10A, and $\mathrm{E} 10 \mathrm{~B})$.

Effects of Parp deletion on non-cachectic control animals. Relative activated NF-kB p50 and p65 levels did not significantly differ in any muscle between either non-cachectic Parp- $1^{-/}$or Parp- $2^{-/-}$ and the non-cachectic control mice (Figs. 6A-6D, E9A, E9B, E10A, and E10B).

\section{Deletions of PARP-1 and -2 favor markers of muscle anabolism}

LC-induced cachexia. Compared to their respective non-cachectic controls, cachectic wild type and Parp $-1^{-/-}$animals did not show any significant difference in activated Akt muscle levels in any study muscle, while in cachectic Parp- $2^{-/-}$mice, activated Akt levels were increased in the gastrocnemius 
but not the diaphragm (Figs. 7A, 7B, E11A, and E11B). In cachectic wild type mice compared to wild type controls, activated mTOR levels were significantly reduced in the diaphragm, while an almost significant decrease was seen in the gastrocnemius $(\mathrm{p}=0.096)$ (Figs. 7C, 7D, E12A, and E12B). No significant differences in activated mTOR levels were seen in the diaphragm or gastrocnemius muscles between cachectic and non-cachectic mice in any of the knockout groups (Figs. 7C, 7D, E12A, and E12B). Compared to non-cachectic controls, no significant differences were detected in activated p70S6K levels in the diaphragm of either cachectic wild type or any of the knockout mice (Figs. 7E and E13A). Activated p70S6K levels were decreased in the gastrocnemius of cachectic wild type mice compared to their non-cachectic controls (Figs. 7F and E13B). Cachectic wild type and Parp- $2^{-/-}$animals showed a significant reduction in mtDNA/nDNA content in both respiratory and limb muscles compared to the corresponding non-cachectic controls (Figs. 7G and $7 \mathrm{H}$, respectively). However, diaphragm or gastrocnemius levels of mtDNA/nDNA did not differ between cachectic and non-cachectic conditions in Parp- $1^{-/-}$mice (Figs. $7 \mathrm{G}$ and $7 \mathrm{H}$, respectively).

Effects of Parp deletion on non-cachectic control animals. No significant differences were seen in activated Akt levels between non-cachectic wild type and any of the control knockout groups of mice (Figs. 7A-7B, E11A and E11B). Diaphragm levels of mTOR protein did not significantly differ between non-cachectic wild type and any of the knockout groups of mice, whereas its levels were significantly greater in the gastrocnemius of non-cachectic Parp- $2^{-/-}$control animals than in wild type mice (Figs. 7C-7D, E12A and E12B). P70S6K protein levels and the ratio of mtDNA/nDNA did not significantly differ in the study muscles between either non-cachectic Parp- $1^{-1-}$ or Parp- $2^{-1-}$ and the non-cachectic wild type mice (Figs. 7E-7H, E13A and E13B).

\section{Attenuation of muscle atrophy by PARP-1 and -2 deletions}

LC-induced cachexia. The proportions of type I and II fibers did not significantly differ between cachectic and non-cachectic conditions in any experimental group of mice (Table 2 and Figs. E14A and E14B). The size of both slow- and fast-twitch fibers was significantly reduced in diaphragm and 
gastrocnemius of cachectic wild type mice compared to the corresponding non-cachectic control muscles (Table 2 and Figs. E14A and E14B). However, in both Parp- $1^{-/-}$and Parp- $2^{-/-}$mice, the size of type I and type II fibers did not significantly differ in the study muscles between cachectic and non-cachectic conditions (Table 2 and Figs. E14A and E14B). Proportions of abnormal muscle fraction, including inflammatory cell and internal nuclei counts were increased in both respiratory and limb muscles in LC-cachectic mice of all experimental groups compared to the corresponding non-cachectic controls (Table 2). Compared to the corresponding non-cachectic controls, TUNELstained nuclei counts were increased in respiratory and limb muscles of wild type, Parp- $1^{-1-}$ and Parp$2^{-/-}$cachectic mice (Table 2 and Figs. E15A and E15B).

Effects of Parp deletion on non-cachectic control animals. Proportions of type I and type II fibers did not significantly differ in the study muscles between wild type and either Parp $-1^{-/-}$or Parp- $2^{-/-}$ non-cachectic control mice (Table 2 and Figs. E14A and E14B). The size of slow-twitch fibers was significantly reduced in the gastrocnemius of non-cachectic Parp- $2^{-/-}$mice compared to non-cachectic wild type animals (Table 2 and Figs. E14A and E14B). Proportions of inflammatory cells were almost significantly increased $(\mathrm{p}=0.055)$ in the diaphragm of Parp- $2^{-/-}$controls compared to wild type non-cachectic animals (Table 2). Proportions of TUNEL-positively stained nuclei did not significantly differ in the study muscles between non-cachectic wild type and any of the knockout mice (Table 2 and Figs. E15A and E15B).

\section{Attenuation of muscle contractile protein loss by PARP-1 and -2 deletions}

LC-induced cachexia. In diaphragm and gastrocnemius of wild type cachectic mice, protein levels of contractile MyHC were reduced compared to the non-cachectic controls (Figs. 8A, 8B, E16A, and E16B). MyHC protein levels also decreased in the diaphragm but not in the gastrocnemius of cachectic Parp- $1^{-/-}$mice compared to Parp- $1^{-/-}$non-cachectic control animals (Figs. 8A, 8B, E16A, and E16B). MyHC levels did not significantly differ in the study muscles between cachectic and non-cachectic Parp-2 $2^{-/-}$animals (Figs. 8A, 8B, E16A, and E16B). No significant differences were 
seen in actin protein levels in the study muscles between cachectic and non-cachectic conditions in any experimental group of mice (Figs. 8C, 8D, E17A, and E17B).

Effects of Parp deletion on non-cachectic control animals. MyHC and actin levels did not significantly differ in the study muscles among any of the non-cachectic control mice (Figs. 8A-8D and E16A-E17B).

\section{Discussion}

Summary of main study findings

The main findings in the investigation were that compared to non-cachectic control wild type animals, in both diaphragm and gastrocnemius muscles of cancer cachectic wild type mice: 1) PARP activity (pADPr levels), protein oxidation, and protein breakdown levels (tyrosine release) were increased, 2) levels of markers of the ubiquitin-proteasome system were greater; 3) mitochondrial SOD2 and contractile myosin protein contents were decreased, 4) NF-кB signaling pathway was activated, and 5) several markers of muscle anabolism were reduced. Specific genetic deletions of either Parp-1 or -2 in the cancer cachectic mice attenuated the rise in levels of muscle protein oxidation and catabolism, markers of ubiquitin-proteasome system, and NF- $\kappa \mathrm{B}$ signaling pathway, while causing an improvement in levels of anabolic markers, muscle atrophy and myosin protein loss, body and muscle weights, and limb muscle strength. Furthermore, the model of LC-induced cachexia has been reproduced and well-validated again in the current investigation. PARP activity was demonstrated to be increased in wild type cachectic mice, while it significantly decreased in the PARP-1 and -2 deficient mice. We believe that the results encountered in the present study enhance existing knowledge in the field of muscle wasting in cancer-induced cachexia. Moreover, deficiency of either PARP-1 or -2 induced several beneficial effects on the cachectic animals and their muscles that are discussed below.

Deletion of PARP-1 and -2 activities attenuated increased muscle oxidative stress and 
proteolysis

The rise in pADPr levels observed in the muscles of the wild type cancer cachectic mice was a major finding in the current study. Furthermore, a significant decrease in pADPr levels was detected in both respiratory and limb muscles of Parp- $1^{-1-}$ and Parp- $2^{-/-}$non-cachectic control mice, confirming the validity and reliability of the genetic deletions of both PARP-1 and -2 proteins in the tissues of the knockout animals. These findings also suggest that PARP probably plays a relevant role in the development of cancer-induced muscle wasting, as the increase in pADPr content was blunted in both muscle types of Parp- $1^{-/-}$and Parp- $2^{-/-}$cancer-cachectic mice.

Oxidative stress has been previously demonstrated to trigger muscle mass loss in patients (Barreiro et al, 2008;Barreiro et al, 2010b;Fermoselle et al, 2012;Marin-Corral et al, 2010;PuigVilanova et al, 2014) and animal models including the current model of cancer cachexia (ChaconCabrera et al, 2014;Fermoselle et al, 2011;Fermoselle et al, 2012;Puig-Vilanova et al, 2014) and to induce the activation of PARP in the nucleus (de et al, 1994;Olah et al, 2015;Ullrich et al, 1999; Ullrich et al, 2000). In the present study, protein oxidation levels were greater, while those of mitochondrial SOD2 were lower in both muscle types of wild type cancer cachectic mice than in the non-cachectic controls. Deletion of PARP-1 and -2 attenuated the rise in protein oxidation and the decrease in SOD2 in both respiratory and limb muscles, suggesting that PARP may underlie oxidant production and alter antioxidant defense in cancer cachectic muscles. These findings are in line with those previously shown in muscle cells, in which resistance to oxidative stress was highly dependent on PARP activation (Olah et al, 2015). In fact, it has also been demonstrated that PARP may activate proteasomal degradation in response to increased oxidative stress in leukemic cells (Ullrich et al, 2000). On the basis of those seminal findings, it would be possible to conclude that PARP may have also mediated enhanced protein breakdown via the proteasome following oxidative stress in respiratory and limb muscles of cancer cachectic mice in the current experimental model. Identification of the nature of the oxidized proteins including histones (Ullrich et al, 1999) and other 
epigenetic changes (Chacon-Cabrera et al, 2015) should be a matter of investigation in future studies. Total muscle protein catabolism as measured by the tyrosine release assay was increased in the diaphragm and gastrocnemius muscles of the cancer cachectic mice. Genetic inhibition of Parp-1 and -2 blunted the rise in protein breakdown in both respiratory and limb muscles of the cancer cachectic animals. Interestingly, PARP-1 genetic deletion, but not PARP-2, induced a significant rise in tyrosine release levels in both diaphragm and gastrocnemius muscles of the non-cachectic animals compared to wild type control mice. These findings are partly in line with those reported by Bai et al (Bai et al, 2011b), who showed a rise in energy expenditure together with increased muscle mitochondrial metabolism, probably as a result of Sirtuin1 activation, in mice that were genetically deficient for PARP-1 enzyme. On the other hand, in a previous study using the same experimental model, the decrease in Sirtuin 1 induced by cancer cachexia was attenuated in muscles of Parp- $1^{-1-}$ and Parp- $2^{-/-}$cachectic mice (Chacon-Cabrera et al, 2015). Taken together, these findings may imply that PARP-1 deletion may lead to a rise in protein catabolism reflected by increased tyrosine release in normal muscles. Future research should aim to investigate this pathway in more detail.

Total protein ubiquitination levels were increased in the cachectic wild type rodents, whereas no differences in this proteolytic marker were detected in either Parp $-1^{-/-}$or Parp- $2^{-/-}$mice between cachectic and non-cachectic conditions. Both PARP-1 and -2 deficiency blunted the rise in protein ubiquitination seen in the respiratory and limb muscles of the cachectic knockout mice probably by reducing the levels of oxidants, as these were shown to trigger muscle mass loss in animal and human studies (Chacon-Cabrera et al, 2014;Puig-Vilanova et al, 2014) and PARP activation induced oxidant production (Olah et al, 2015; Ullrich et al, 1999;Ullrich et al, 2000).

In keeping with, levels of markers of the ubiquitin-proteasome pathway such as the $20 \mathrm{~S}$ proteasome C8 subunit and that of the E3 ligase atrogin-1 were also significantly increased in the diaphragm and gastrocnemius muscles of the cachectic wild type rodents compared to the non-tumor controls. These findings are in agreement with previous studies, in which markers of this proteolytic 
system were consistently upregulated in models of muscle wasting (Chacon-Cabrera et al, 2014;Fermoselle et al, 2011) including patients with cachexia (Fermoselle et al, 2012;Puig-Vilanova et al, 2014). Importantly, in both respiratory and limb muscles of Parp- $1^{-1 /}$ and Parp- $2^{-1 /}$ cachectic mice, levels of those two proteolytic markers did not differ from those observed in their respective non-cachectic controls. On the other hand, levels of the E3 ligases TRIM-32 and MURF-1 did not significantly differ between cachectic and non-cachectic control mice in any of the study muscles. Hence, these findings suggest that atrogin-1 is the key muscle-specific ligase involved in proteasomal degradation of proteins in the respiratory and limb muscles in this experimental model of cachexia.

In a previous investigation (Chacon-Cabrera et al, 2014), we demonstrated that NF-kB and MAPK were the predominant signaling pathways driving muscle mass loss in this experimental model of cancer cachexia. Additionally, in the same cachectic wild type mice, transcriptional activity of NF-kB was significantly greater in the gastrocnemius muscles than in the non-cachectic control mice (Chacon-Cabrera et al, 2014). In agreement with these findings, in the current investigation, NF-kB signaling pathway was also activated in the diaphragm and gastrocnemius muscles of the cachectic wild type animals. The attenuation in proteolytic degradation seen in the muscles of the cachectic knockout animals could be partly the result of decreased NF-KB transcriptional activity induced by PARP enzyme deficiency, as was shown to occur in previous studies (Hassa and Hottiger, 1999;Oliver et al, 1999).

The previously reported decrease in the rate of myofibrilar protein synthesis observed in models of cachexia (White JP et al, 2012; White et al, 2011;Toth et al, 2013) and aging (Fry et al, 2011) may also partly account for the reduced levels of myosin protein in the cancer cachectic muscles of wild type animals seen in the current study. Additionally, reductions in myofibrilar protein content may also account for the smaller fiber sizes of slow- and fast-twitch fibers observed in both muscle types of the cachectic wild type mice in the investigation. Future studies should be designed in order to 
specifically explore myofibrilar protein synthesis in cancer-induced cachexia in this animal model and whether reduced protein synthesis or enhanced protein catabolism play a predominant role in the process of muscle mass loss. In the study, protein levels of MyHC, a major target for proteolysis in skeletal muscles, were significantly lower in muscles of the wild type cachectic mice. These findings are in line with results previously reported by our group on diaphragm (Marin-Corral et al, 2009) and quadriceps muscles of patients with advanced COPD and cancer cachexia (Fermoselle et al, 2012;Puig-Vilanova et al, 2014), as well as in muscles of mice with emphysema-induced cachexia (Fermoselle et al, 2011;Salazar-Degracia et al, 2016). A relevant finding in the investigation was the attenuation of the decrease in MyHC protein content observed in the study muscles induced by PARP-1 and -2 genetic deletions, especially in the gastrocnemius, of the cachectic animals probably through attenuation of both oxidative stress and increased myofibrillar proteolysis. Moreover, the attenuation of protein degradation may also account for the improvements observed in body and muscle weights and limb muscle strength in Parp- $1^{-/-}$and Parp- $2^{-1-}$ cachectic mice. On the other hand, the study of the potential contribution of PARP activation to muscle protein synthesis in models of cachexia also deserves special attention in future studies.

\section{Genetic deletion of PARP-1 and -2 proteins promoted the expression of anabolic markers}

Levels of mTOR were lower in the diaphragm and gastrocnemius and those of p70SK6 also in the latter muscles of the cachectic wild type mice compared to the non-tumor controls. These findings are in agreement with those reported in models of colon cancer cachexia in mice (White et al, 2011) and in muscles from cancer-cachectic and elderly subjects (Fry CS et al, 2011; Toth et al, 2013), in which mTOR signaling was suppressed together with a decline in the rate of myofibrilar protein synthesis. Importantly, in cachectic Parp $-1^{-/-}$and Parp $-2^{-/-}$mice, the decrease in mTOR levels was attenuated in both muscles, thus suggesting that PARP-1 and -2 may interact with mTOR signaling in this model of muscle wasting, especially in the limb muscle, in which mTOR levels were even greater in non-cachectic control Parp- $2^{-/-}$mice. Indeed, previous studies have shown that 
pharmacological inhibitors of PARP prevent mTOR downregulation through its role in the modulation of adenosine monophosphate-activated protein kinase pathways (Ethier et al, 2012).

Mitochondrial content as measured by the ratio of mitochondrial to nuclear DNA was reduced in diaphragm and gastrocnemius muscles of cachectic wild type animals compared to non-cachectic controls. These results are in line with those recently reported in other investigations, in which mitochondrial respiratory chain dysfunction (Fermoselle et al, 2013) and mitochondrial content impairment was shown to occur early in the initiation of cachexia (White JP et al, 2012) and in muscles of rats bearing the Yoshida ascites hepatoma (Fontes-Oliveira et al, 2014;Fontes-Oliveira et al, 2013). Interestingly, in cachectic Parp- $1^{-1-}$ and Parp- $2^{-1-}$ mice (only the diaphragm), the reduction in mitochondrial content was attenuated in muscles of the cachectic rodents. These findings are in line with previous data showing an improvement in mitochondrial content upon inhibition of PARP1, probably via Sirtuin1 activity (Bai et al, 2015;Rajamohan et al, 2009). Depletion of PARP-2 also resulted in enhanced Sirtuin 1 activity and increased mitochondrial content in several in vitro models (Bai et al, 2011a;Mohamed et al, 2014). Differences between Parp- $1^{-/-}$and Parp- $2^{-/-}$cachectic mice in mitochondrial content observed in this study may be the result of the distinctive interaction of PARP1 and -2 with Sirtuin1 promoter: while PARP-2 does not modify Sirtuin1 promoter activity, PARP-2 suppresses its activity (Bai et al, 2011b). These findings warrant special attention in further studies in which the specific role of PARP-1 and -2 in mitochondrial remodeling and function should be explored. The potential beneficial effects of PARP deletion on mitochondrial respiratory chain function and oxidative metabolism (Bai et al, 2011b;Bai et al, 2011a;Bai et al, 2015) should also be a matter of research in future investigations focused on the thorough assessment of these organelles in models of cancer-induced cachexia (Fontes-Oliveira et al, 2013; Tzika et al, 2013).

\section{Study limitations}

It is likely that the reduction in tumor burden observed in both groups of knockout mice may have partly contributed to favoring body and muscle mass gain in the mice. In fact, deficiency of both 
PARP-1 and -2 induced a reduction in tumor weights in the animals, as has recently been demonstrated through several biological mechanisms (Chacon-Cabrera et al, 2015;Mateu-Jimenez et al, 2016). In the current investigation, diaphragmatic contractile function was not measured as the main focus was to assess the effects of PARP1- and -2 deletions in the peripheral muscles of the target mice. Moreover, such studies would have implied the use of a different approach and a significantly greater number of animals for the in vitro contractility studies, which was not allowed for ethical reasons in the institution. Indeed, in this investigation, the assessment of the biological pathways whereby PARP deletion may attenuate muscle mass loss in cancer-induced cachexia was prioritized over other types of experiments.

Another limitation is related to the lack of measurements on the progression of tumor size throughout the study protocol in the tumor-bearing animals. In the study, tumor weights were only available at the time of sacrifice in all experimental groups, partly because the investigation focused on the assessment of the tumor effects on the actual cachectic muscles. Moreover, the weights of organs such as the liver or heart were not available in all the study animals. As no significant differences were detected in body weight gain among the non-tumor control groups of animals, and an improvement was seen in Parp $-1^{-/-}$and Parp- $2^{-/-}$cachectic mice compared to their respective nontumor controls, we believe that it is not a major limitation in the study. Indeed, a major strength in the investigation was that the potential beneficial effects of PARP-1 and PARP-2 genetic deletions have been explored independently in two different groups of knockout mice from the following perspectives: the analyses of biological events involved in muscle oxidative stress, catabolism, anabolism, and signaling in the context of a reproducible mouse model of cancer-induced cachexia, as confirmed by the reduced whole body and muscle weights, and limb strength and the presence of muscle atrophy. Future research should focus on the assessment of whether selective pharmacological inhibitors of PARP-1 and -2 exert similar beneficial effects on muscles in models of cancer cachexia including those in clinical settings, since pharmacological inhibitors of PARP-1 and 
-2 are currently available for the treatment of certain cancer types. Nonetheless, prior to establishing a beneficial effect on muscle mass loss and metabolism of PARP pharmacological inhibition in patients with cancer-induced cachexia, the selective role of either PARP-1 or PARP-2 enzymes in protein catabolism and anabolism, muscle phenotype and function deserved to be particularly studied in an experimental model of cancer-induced cachexia using specific transgenic mice.

\section{Conclusions}

In respiratory and limb muscles of tumor-bearing mice with cachexia, PARP activity pathway underlies enhanced protein catabolism through increased oxidative stress, activation of the ubiquitinproteasome system, and NF-kB signaling. The reduction in contractile myosin content and atrophy signature of the myofibers was substantially attenuated in respiratory and limb muscles of the cachectic Parp- $1^{-/-}$or Parp- $2^{-/-}$mice, while no effects were seen in other structural features. Markers of muscle anabolism partly improved in both diaphragm and gastrocnemius muscles of the cachectic PARP-deficient mice, especially in cachectic Parp- $1^{-/-}$animals. The expression pattern of the biological events observed in the study muscles was similar in Parp $-1^{-/-}$and Parp- $2^{-/-}$LC-cachectic animals, except for mitochondrial content. Collectively, the study findings imply that activation of either PARP-1 or -2 is likely to play a relevant role in muscle protein catabolism via oxidative stress, NF-kB signaling and enhanced proteasomal degradation in cancer-induced cachexia. Despite the potential limitations of PARP activity inhibition, since it plays a key role in DNA maintenance, exploration of its reliability and likely applicability as a possible target for future therapeutic interventions deserves attention in models of cancer-induced cachexia. 


\section{ACKNOWLEDGEMENTS}

The authors are thankful to Dr. Juan Martin-Caballero and Mr. Francisco Sanchez for their technical assistance with the animal experiments, to Ms. Maria Cortes-Badia and Ms. Ida Salmela for their support with the muscle structure experiments, and to Ms. Coral Ampurdanes for her contribution to mouse genotyping.

Editorial support: None to declare.

\section{CONFLICT OF INTEREST}

The authors declare no conflict of interest in relation to this study.

\section{AUTHOR CONTRIBUTIONS}

Alba Chacon-Cabrera: animal experiments, molecular biology and muscle structure experiments, data analyses, and results preparation

Mercè Mateu-Jiménez: assessment of the levels of PARP activity in the muscles, graphical representation, and preparation of the final version of all the study results

Klaus Langohr: Statistical analyses, assessment of data presentation and graphical representation

Clara Fermoselle: animal and molecular biology experiments

Elena García-Arumí: mitochondrial experiments and analyses

Antoni L. Andreu: mitochondrial experiments and analyses

José Yélamos: animal experiments, data interpretation, and manuscript intellectual input

Esther Barreiro: study design, data analyses and interpretation, results preparation, and manuscript writing final version

John Wiley \& Sons, Inc. 


\section{Literature Cited}

Alvarez FV, Trueba IM, Sanchis JB, Lopez-Rodo LM, Rodriguez Suarez PM, de Cos Escuin JS, Barreiro E, Henar Borrego PM, Vicente CD, Aldeyturriaga JF, Gamez GP, Garrido LP, Leon AP, Izquierdo Elena JM, Novoa Valentin NM, Rivas de Andres JJ, Crespo IR, Velazquez AS, Seijo Maceiras LM, Reina SS, Bujanda DA, Avila Martinez RJ, de Granda Orive JI, Martinez EH, Gude VD, Flor RE, Freixinet Gilart JL, Garcia Jimenez MD, Alarza FH, Sarmiento SH, Honguero Martinez AF, Jimenez Ruiz CA, Sanz IL, Mariscal de AA, Martinez VP, Menal MP, Perez LM, Olmedo Garcia ME, Rombola CA, Arregui IS, Somiedo GM, V, Trivino Ramirez AI, Trujillo Reyes JC, Vallejo C, Lozano PV, Simo GV, Zulueta JJ (2016). Recommendations of the Spanish Society of Pneumology and Thoracic Surgery on the diagnosis and treatment of non-small-cell lung cancer. Arch Bronconeumol 52 Suppl 1:2-62.

Andreu AL, Martinez R, Marti R, Garcia-Arumi E (2009). Quantification of mitochondrial DNA copy number: pre-analytical factors. Mitochondrion 9:242-246.

Bai P, Canto C, Brunyanszki A, Huber A, Szanto M, Cen Y, Yamamoto H, Houten SM, Kiss B, Oudart H, Gergely P, Menissier-de MJ, Schreiber V, Sauve AA, Auwerx J (2011a). PARP-2 regulates SIRT1 expression and whole-body energy expenditure. Cell Metab 13:450-460.

Bai P, Canto C, Oudart H, Brunyanszki A, Cen Y, Thomas C, Yamamoto H, Huber A, Kiss B, Houtkooper RH, Schoonjans K, Schreiber V, Sauve AA, Menissier-de MJ, Auwerx J (2011b). PARP-1 inhibition increases mitochondrial metabolism through SIRT1 activation. Cell Metab 13:461-468.

Bai P, Nagy L, Fodor T, Liaudet L, Pacher P (2015). Poly(ADP-ribose) polymerases as modulators of mitochondrial activity. Trends Endocrinol Metab 26:75-83.

Barreiro E (2017). Skeletal Muscle Dysfunction in COPD: Novelties in The Last Decade. Arch Bronconeumol 53:43-44.

Barreiro E, Marin-Corral J, Sanchez F, Mielgo V, Alvarez FJ, Galdiz JB, Gea J (2010a). Reference values of respiratory and peripheral muscle function in rats. J Anim Physiol Anim Nutr (Berl) 94:e393-e401.

Barreiro E, Peinado VI, Galdiz JB, Ferrer E, Marin-Corral J, Sanchez F, Gea J, Barbera JA (2010b). Cigarette smoke-induced oxidative stress: A role in chronic obstructive pulmonary disease skeletal muscle dysfunction. Am J Respir Crit Care Med 182:477-488.

Barreiro E, Puig-Vilanova E, Marin-Corral J, Chacon-Cabrera A, Salazar-Degracia A, Mateu X, Puente-Maestu L, Garcia-Arumi E, Andreu AL, Molina L (2016). Therapeutic Approaches in Mitochondrial Dysfunction, Proteolysis, and Structural Alterations of Diaphragm and Gastrocnemius in Rats With Chronic Heart Failure. J Cell Physiol 231:1495-1513.

Barreiro E, Schols AM, Polkey MI, Galdiz JB, Gosker HR, Swallow EB, Coronell C, Gea J (2008). Cytokine profile in quadriceps muscles of patients with severe COPD. Thorax 63:100-107.

Burkle A, Virag L (2013). Poly(ADP-ribose): PARadigms and PARadoxes. Mol Aspects Med 34:1046-1065.

Carter CS, Cesari M, Ambrosius WT, Hu N, Diz D, Oden S, Sonntag WE, Pahor M (2004). Angiotensin-converting enzyme inhibition, body composition, and physical performance in aged 
rats. J Gerontol A Biol Sci Med Sci 59:416-423.

Chacon-Cabrera A, Fermoselle C, Salmela I, Yelamos J, Barreiro E (2015). MicroRNA expression and protein acetylation pattern in respiratory and limb muscles of Parp-1(-/-) and Parp-2(-/-) mice with lung cancer cachexia. Biochim Biophys Acta 1850:2530-2543.

Chacon-Cabrera A, Fermoselle C, Urtreger AJ, Mateu-Jimenez M, Diament MJ, De Kier Joffe ED, Sandri M, Barreiro E (2014). Pharmacological strategies in lung cancer-induced cachexia: effects on muscle proteolysis, autophagy, structure, and weakness. J Cell Physiol 229:1660-1672.

Chacon-Cabrera A, Gea J, Barreiro E (2016a). Short- and Long-Term Hindlimb Immobilization and Reloading: Profile of Epigenetic Events in Gastrocnemius. J Cell Physiol.

Chacon-Cabrera A, Lund-Palau H, Gea J, Barreiro E (2016b). Time-Course of Muscle Mass Loss, Damage, and Proteolysis in Gastrocnemius following Unloading and Reloading: Implications in Chronic Diseases. PLoS One 11:e0164951.

Corral J, Yelamos J, Hernandez-Espinosa D, Monreal Y, Mota R, Arcas I, Minano A, Parrilla P, Vicente V (2005). Role of lipopolysaccharide and cecal ligation and puncture on blood coagulation and inflammation in sensitive and resistant mice models. Am J Pathol 166:1089-1098.

de Murcia JM, Niedergang C, Trucco C, Ricoul M, Dutrillaux B, Mark M, Oliver FJ, Masson M, Dierich A, LeMeur M, Walztinger C, Chambon P, de MG (1997). Requirement of poly(ADP-ribose) polymerase in recovery from DNA damage in mice and in cells. Proc Natl Acad Sci U S A 94:73037307.

de MG, Schreiber V, Molinete M, Saulier B, Poch O, Masson M, Niedergang C, Menissier de MJ (1994). Structure and function of poly(ADP-ribose) polymerase. Mol Cell Biochem 138:15-24.

Diament MJ, Garcia C, Stillitani I, Saavedra VM, Manzur T, Vauthay L, Klein S (1998). Spontaneous murine lung adenocarcinoma (P07): A new experimental model to study paraneoplastic syndromes of lung cancer. Int J Mol Med 2:45-50.

Diaz MC, Ospina-Tascon GA, Salazar CB (2014). Respiratory muscle dysfunction: a multicausal entity in the critically ill patient undergoing mechanical ventilation. Arch Bronconeumol 50:73-77.

Ethier C, Tardif M, Arul L, Poirier GG (2012). PARP-1 modulation of mTOR signaling in response to a DNA alkylating agent. PLoS One 7:e47978.

Evans WJ, Morley JE, Argiles J, Bales C, Baracos V, Guttridge D, Jatoi A, Kalantar-Zadeh K, Lochs H, Mantovani G, Marks D, Mitch WE, Muscaritoli M, Najand A, Ponikowski P, Rossi FF, Schambelan M, Schols A, Schuster M, Thomas D, Wolfe R, Anker SD (2008). Cachexia: a new definition. Clin Nutr 27:793-799.

Fearon K, Strasser F, Anker SD, Bosaeus I, Bruera E, Fainsinger RL, Jatoi A, Loprinzi C, MacDonald N, Mantovani G, Davis M, Muscaritoli M, Ottery F, Radbruch L, Ravasco P, Walsh D, Wilcock A, Kaasa S, Baracos VE (2011). Definition and classification of cancer cachexia: an international consensus. Lancet Oncol 12:489-495.

Fermoselle C, Garcia-Arumi E, Puig-Vilanova E, Andreu AL, Urtreger AJ, De Kier Joffe ED, Tejedor A, Puente-Maestu L, Barreiro E (2013). Mitochondrial dysfunction and therapeutic approaches in respiratory and limb muscles of cancer cachectic mice. Exp Physiol 98:1349-1365. 
Fermoselle C, Rabinovich R, Ausin P, Puig-Vilanova E, Coronell C, Sanchez F, Roca J, Gea J, Barreiro E (2012). Does oxidative stress modulate limb muscle atrophy in severe COPD patients? Eur Respir J 40:851-862.

Fermoselle C, Sanchez F, Barreiro E (2011). [Reduction of muscle mass mediated by myostatin in an experimental model of pulmonary emphysema]. Arch Bronconeumol 47:590-598.

Fontes-Oliveira CC, Busquets S, Fuster G, Ametller E, Figueras M, Olivan M, Toledo M, LopezSoriano FJ, Qu X, Demuth J, Stevens P, Varbanov A, Wang F, Isfort RJ, Argiles JM (2014). A differential pattern of gene expression in skeletal muscle of tumor-bearing rats reveals dysregulation of excitation-contraction coupling together with additional muscle alterations. Muscle Nerve 49:233248.

Fontes-Oliveira CC, Busquets S, Toledo M, Penna F, Paz AM, Sirisi S, Silva AP, Orpi M, Garcia A, Sette A, Ines GM, Olivan M, Lopez-Soriano FJ, Argiles JM (2013). Mitochondrial and sarcoplasmic reticulum abnormalities in cancer cachexia: altered energetic efficiency? Biochim Biophys Acta 1830:2770-2778.

Fry CS, Drummond MJ, Glynn EL, Dickinson JM, Gundermann DM, Timmerman KL, Walker DK, Dhanani S, Volpi E, Rasmussen BB (2011). Aging impairs contraction-induced human skeletal muscle mTORC1 signaling and protein synthesis. Skeletal muscle 1:1-11.

Fry CS, Drummond MJ, Glynn EL, Dickinson JM, Gundermann DM, Timmerman KL, Walker DK, Dhanani S, Volpi E, Rasmussen BB (2011). Aging impairs contraction-induced human skeletal muscle mTORC1 signaling and protein synthesis. Skelet Muscle 1:11.

Ha HC, Snyder SH (1999). Poly(ADP-ribose) polymerase is a mediator of necrotic cell death by ATP depletion. Proc Natl Acad Sci U S A 96:13978-13982.

Hassa PO, Hottiger MO (1999). A role of poly (ADP-ribose) polymerase in NF-kappaB transcriptional activation. Biol Chem 380:953-959.

Hothorn T, Bretz F, Westfall P (2008). Simultaneous inference in general parametric models. Biom J 50:346-363.

Jagtap P, Soriano FG, Virag L, Liaudet L, Mabley J, Szabo E, Hasko G, Marton A, Lorigados CB, Gallyas F, Jr., Sumegi B, Hoyt DG, Baloglu E, VanDuzer J, Salzman AL, Southan GJ, Szabo C (2002). Novel phenanthridinone inhibitors of poly (adenosine 5'-diphosphate-ribose) synthetase: potent cytoprotective and antishock agents. Crit Care Med 30:1071-1082.

Kiefmann R, Heckel K, Doerger M, Schenkat S, Kupatt C, Stoeckelhuber M, Wesierska-Gadek J, Goetz AE (2004). Role of PARP on iNOS pathway during endotoxin-induced acute lung injury. Intensive Care Med 30:1421-1431.

Lai YC, Aneja RK, Satchell MA, Clark RS (2011). Detecting and quantifying pADPr in vivo. Methods Mol Biol 780:117-134.

Leiro-Fernandez V, Mouronte-Roibas C, Ramos-Hernandez C, Botana-Rial M, Gonzalez-Pineiro A, Garcia-Rodriguez E, Represas-Represas C, Fernandez-Villar A (2014). Changes in clinical presentation and staging of lung cancer over two decades. Arch Bronconeumol 50:417-421.

Marin-Corral J, Fontes CC, Pascual-Guardia S, Sanchez F, Olivan M, Argiles JM, Busquets S, 
Lopez-Soriano FJ, Barreiro E (2010). Redox balance and carbonylated proteins in limb and heart muscles of cachectic rats. Antioxid Redox Signal 12:365-380.

Marin-Corral J, Minguella J, Ramirez-Sarmiento AL, Hussain SN, Gea J, Barreiro E (2009). Oxidised proteins and superoxide anion production in the diaphragm of severe COPD patients. Eur Respir J 33:1309-1319.

Mateu-Jimenez M, Cucarull-Martinez B, Yelamos J, Barreiro E (2016). Reduced tumor burden through increased oxidative stress in lung adenocarcinoma cells of PARP-1 and PARP-2 knockout mice. Biochimie 121:278-286.

McDermott-Roe C, Ye J, Ahmed R, Sun XM, Serafin A, Ware J, Bottolo L, Muckett P, Canas X, Zhang J, Rowe GC, Buchan R, Lu H, Braithwaite A, Mancini M, Hauton D, Marti R, Garcia-Arumi E, Hubner N, Jacob H, Serikawa T, Zidek V, Papousek F, Kolar F, Cardona M, Ruiz-Meana M, Garcia-Dorado D, Comella JX, Felkin LE, Barton PJ, Arany Z, Pravenec M, Petretto E, Sanchis D, Cook SA (2011). Endonuclease $G$ is a novel determinant of cardiac hypertrophy and mitochondrial function. Nature 478:114-118.

Mohamed JS, Hajira A, Pardo PS, Boriek AM (2014). MicroRNA-149 inhibits PARP-2 and promotes mitochondrial biogenesis via SIRT-1/PGC-1alpha network in skeletal muscle. Diabetes 63:1546-1559.

Muscaritoli M, Bossola M, Aversa Z, Bellantone R, Rossi FF (2006). Prevention and treatment of cancer cachexia: new insights into an old problem. Eur J Cancer 42:31-41.

Olah G, Szczesny B, Brunyanszki A, Lopez-Garcia IA, Gero D, Radak Z, Szabo C (2015). Differentiation-Associated Downregulation of Poly(ADP-Ribose) Polymerase-1 Expression in Myoblasts Serves to Increase Their Resistance to Oxidative Stress. PLoS One 10:e0134227.

Oliver FJ, Menissier-de MJ, Nacci C, Decker P, Andriantsitohaina R, Muller S, de la Rubia G, Stoclet JC, de MG (1999). Resistance to endotoxic shock as a consequence of defective NF-kappaB activation in poly (ADP-ribose) polymerase-1 deficient mice. EMBO J 18:4446-4454.

Penalver Cuesta JC, Jorda AC, Mancheno FN, Ceron Navarro JA, de Aguiar QK, Arraras MM, Vera Sempere FJ, Padilla Alarcon JD (2015). Prognostic Factors in Non-Small Cell Lung Cancer Less than 3 Centimeters: Actuarial Analysis, Accumulative Incidence and Risk Groups. Arch Bronconeumol.

Puig-Vilanova E, Rodriguez DA, Lloreta J, Ausin P, Pascual-Guardia S, Broquetas J, Roca J, Gea J, Barreiro E (2014). Oxidative stress, redox signaling pathways, and autophagy in cachectic muscles of male patients with advanced COPD and lung cancer. Free Radic Biol Med 79C:91-108.

Rajamohan SB, Pillai VB, Gupta M, Sundaresan NR, Birukov KG, Samant S, Hottiger MO, Gupta MP (2009). SIRT1 promotes cell survival under stress by deacetylation-dependent deactivation of poly(ADP-ribose) polymerase 1. Mol Cell Biol 29:4116-4129.

Salazar-Degracia A, Blanco D, Vila-Ubach M, de BG, de Solorzano CO, Montuenga LM, Barreiro E (2016). Phenotypic and metabolic features of mouse diaphragm and gastrocnemius muscles in chronic lung carcinogenesis: influence of underlying emphysema. J Transl Med 14:244.

Sanchez dC-E (2015). Prognostic Factors in Stage I Lung Cancer. Arch Bronconeumol 51:427-428. 
Sanchez-Salcedo P, Berto J, de-Torres JP, Campo A, Alcaide AB, Bastarrika G, Pueyo JC, Villanueva A, Echeveste JI, Lozano MD, Garcia-Velloso MJ, Seijo LM, Garcia J, Torre W, Pajares MJ, Pio R, Montuenga LM, Zulueta JJ (2015). Lung Cancer Screening: Fourteen Year Experience of the Pamplona Early Detection Program (P-IELCAP). Arch Bronconeumol.

Sebio R, Yanez-Brage MI, Gimenez-Moolhuyzen E, Valenza MC, Reychler G, Cahalin LP (2015). Impact of a pre-operative pulmonary rehabilitation program on functional performance in patients undergoing video-assisted thoracic surgery for lung cancer. Arch Bronconeumol.

Toth MJ, Miller MS, Callahan DM, Sweeny AP, Nunez I, Grunberg SM, Der-Torossian H, Couch ME, Dittus K (2013). Molecular mechanisms underlying skeletal muscle weakness in human cancer: reduced myosin-actin cross-bridge formation and kinetics. J Appl Physiol 114:858-868.

Tzika AA, Fontes-Oliveira CC, Shestov AA, Constantinou C, Psychogios N, Righi V, Mintzopoulos D, Busquets S, Lopez-Soriano FJ, Milot S, Lepine F, Mindrinos MN, Rahme LG, Argiles JM (2013). Skeletal muscle mitochondrial uncoupling in a murine cancer cachexia model. Int J Oncol 43:886894.

Ullrich O, Ciftci O, Hass R (2000). Proteasome activation by poly-ADP-ribose-polymerase in human myelomonocytic cells after oxidative stress. Free Radic Biol Med 29:995-1004.

Ullrich O, Reinheckel T, Sitte N, Hass R, Grune T, Davies KJ (1999). Poly-ADP ribose polymerase activates nuclear proteasome to degrade oxidatively damaged histones. Proc Natl Acad Sci U S A 96:6223-6228.

Vaschetto R, Kuiper JW, Chiang SR, Haitsma JJ, Juco JW, Uhlig S, Plotz FB, Della CF, Zhang H, Slutsky AS (2008). Inhibition of poly(adenosine diphosphate-ribose) polymerase attenuates ventilator-induced lung injury. Anesthesiology 108:261-268.

von HS, Anker SD (2010). Cachexia as a major underestimated and unmet medical need: facts and numbers. J Cachexia Sarcopenia Muscle 1:1-5.

White JP, Puppa MJ, Sato S, Gao S, Price RL, Baynes JW, Kostek MC, Matesic LE, Carson JA (2012). IL-6 regulation on skeletal muscle mitochondrial remodeling during cancer cachexia in the ApcMin/+ mouse. Skeletal muscle 2:14.

White JP, Baynes JW, Welle SL, Kostek MC, Matesic LE, Sato S, Carson JA (2011). The regulation of skeletal muscle protein turnover during the progression of cancer cachexia in the $\mathrm{Apc}(\mathrm{Min} /+)$ mouse. PLoS One 6:e24650.

Whittemore LA, Song K, Li X, Aghajanian J, Davies M, Girgenrath S, Hill JJ, Jalenak M, Kelley P, Knight A, Maylor R, O'Hara D, Pearson A, Quazi A, Ryerson S, Tan XY, Tomkinson KN, Veldman GM, Widom A, Wright JF, Wudyka S, Zhao L, Wolfman NM (2003). Inhibition of myostatin in adult mice increases skeletal muscle mass and strength. Biochem Biophys Res Commun 300:965971.

$\mathrm{Xu}$ J, Knutson MD, Carter CS, Leeuwenburgh C (2008). Iron accumulation with age, oxidative stress and functional decline. PLoS One 3:e2865.

Yelamos J, Farres J, Llacuna L, Ampurdanes C, Martin-Caballero J (2011). PARP-1 and PARP-2: New players in tumour development. Am J Cancer Res 1:328-346. 
Zheng J, Devalaraja-Narashimha K, Singaravelu K, Padanilam BJ (2005). Poly(ADP-ribose) polymerase-1 gene ablation protects mice from ischemic renal injury. Am J Physiol Renal Physiol 288:F387-F398.

Zhou X, Wang JL, Lu J, Song Y, Kwak KS, Jiao Q, Rosenfeld R, Chen Q, Boone T, Simonet WS, Lacey DL, Goldberg AL, Han HQ (2010). Reversal of cancer cachexia and muscle wasting by ActRIIB antagonism leads to prolonged survival. Cell 142:531-543.

John Wiley \& Sons, Inc. 


\section{FIGURE LEGENDS}

Fig. 1A Mean values and standard deviations of the progression of the actual body weights in mice from all the experimental groups are represented in the graph. Each experimental group is represented by the following signs: non-cachectic control wild type animals (light-blue circles, $\mathrm{N}=12$ ), LC-cachectic wild type mice (red squares, $\mathrm{N}=14$ ), non-cachectic control Parp- ${ }^{-/}$rodents (green triangles, $\mathrm{N}=8$ ), LC-cachectic Parp- $1^{-/}$mice (dark-blue squares, $\mathrm{N}=12$ ), non-cachectic control Parp $-2^{-/-}$rodents (turquois squares, $\mathrm{N}=6$ ), and LC-cachectic Parp- $2^{-/-}$animals (orange circles, $\mathrm{N}=6$ ) over the study period (one month). Statistical significance is represented as follows: **, $\mathrm{p} \leq 0.01, * * *$, $\mathrm{p} \leq 0.001$, and n.s., non-significant differences between either wild type, Parp- $1^{-/-}$, or Parp- $2^{-/-}$LCcachectic mice and their respective control (non-tumor) rodents. Statistical analyses were conducted using one-way analysis of variance (ANOVA), in which Dunnett's post hoc analysis was used to adjust for multiple comparisons among the study groups.

Fig. 1B-C Mean values and the corresponding 95\% confidence intervals of the percentage of positively-stained nuclei for poly-ADP ribosylation (a marker of PARP activity) in the diaphragm (panel B) and gastrocnemius (panel C). For statistical analysis purposes, the following animals were used in each group: non-cachectic control wild type $(\mathrm{N}=8)$, LC-cachectic wild type $(\mathrm{N}=8)$, noncachectic control Parp-1 ${ }^{-/-}(\mathrm{N}=8)$, LC-cachectic Parp-1 ${ }^{-/-}(\mathrm{N}=8)$, non-cachectic control Parp-2 $2^{-/-}(\mathrm{N}=6)$, and LC-cachectic Parp- $2^{-/-}(\mathrm{N}=6)$. Non-cachectic control groups are represented in white bars, while LC-cachectic groups are represented in grey bars. Definition of abbreviations: LC, Lung cancer; PARP, poly-ADP ribose polymerase; ADPr, ADP ribosylation. Statistical significance is represented as follows: ${ }^{* *}, \mathrm{p} \leq 0.001$, and n.s., non-significant differences between either wild type, Parp- $1^{-/-}$, or Parp- $2^{-/-}$LC-cachectic mice and the corresponding control (non-tumor) mice; $\dagger, \mathrm{p} \leq 0.05, \dagger \dagger, \mathrm{p} \leq 0.01$ and $+\dagger \dagger, p \leq 0.001$ between any of the non-cachectic control knockout animals and control (nontumor) wild type mice. Comparisons were assessed using ANOVA models that included genotype, 
Fig. 2A-F Mean values and the corresponding 95\% confidence intervals of total carbonylated proteins (panels A and B), SOD2 (panels C and D), and SOD1 (panels E and F) in the diaphragm and gastrocnemius, as measured by optical densities in arbitrary units (OD, a.u.). For statistical analysis purposes, the following animals were used in each group: non-cachectic control wild type $(\mathrm{N}=7)$, LC-cachectic wild type $(\mathrm{N}=8)$, non-cachectic control Parp- $1^{-/}(\mathrm{N}=7)$, LC-cachectic Parp- $1^{-/-}(\mathrm{N}=8)$, non-cachectic control Parp-2 $2^{-/-}(\mathrm{N}=3)$, and LC-cachectic Parp-2 $2^{-/-}(\mathrm{N}=5)$. Non-cachectic control groups are represented in white bars, while LC-cachectic groups are represented in grey bars. Definition of abbreviations: LC, Lung cancer; PARP, poly-ADP ribose polymerase; SOD, superoxide dismutase; OD, optical densities; a.u., arbitrary units. Statistical significance is represented as follows: $*, p \leq 0.05, * *, p \leq 0.01$, ***, $\mathrm{p} \leq 0.001$ and n.s., non-significant differences between either wild type, Parp- $1^{-/-}$, or Parp- $2^{-/-}$LC-cachectic mice and the corresponding noncachectic control mice. Comparisons were assessed using ANOVA models that included genotype, cancer, and the interaction of both.

Fig. 3A-B Mean values and the corresponding 95\% confidence intervals of muscle proteolysis as measured using the tyrosine release assay $(\mathrm{nmol} / \mathrm{mg} / 2 \mathrm{~h}$ ) in the diaphragm (panel A) and gastrocnemius (panel B) muscles of the following experimental groups: non-cachectic control wild type $(\mathrm{N}=10)$, LC-cachectic wild type $(\mathrm{N}=10)$, non-cachectic control Parp- $1^{-/-}(\mathrm{N}=8)$, LC-cachectic Parp- $1^{-/-}(\mathrm{N}=12)$, non-cachectic control Parp-2 ${ }^{-/-}(\mathrm{N}=6)$, and LC-cachectic Parp-2 $2^{-/-}(\mathrm{N}=6)$. Noncachectic control groups are represented in white bars, while LC-cachectic groups are represented in grey bars. Statistical significance is represented as follows: *, $\mathrm{p} \leq 0.05$, and n.s., non-significant differences between either wild type, Parp- $1^{-/-}$, or Parp- $2^{-/-}$LC-cachectic mice and the corresponding non-cachectic control rodents, $\dagger+\mathrm{p} \leq 0.01$ between any of the non-cachectic control knockout animals and control (non-tumor) wild type mice. Comparisons were assessed using ANOVA models that included genotype, cancer, and the interaction of both.

Fig. 4A-D Mean values and the corresponding 95\% confidence intervals of total protein 
ubiquitination levels (panels A and B), and 20S proteasome C8 subunit content (panels C and D) in the diaphragm and gastrocnemius, as measured by optical densities in arbitrary units (OD, a.u.). For statistical analysis purposes, the following animals were used in each group: non-cachectic control wild type $(\mathrm{N}=7)$, LC-cachectic wild type $(\mathrm{N}=8)$, non-cachectic control Parp-1 ${ }^{-/-}(\mathrm{N}=7)$, LC-cachectic Parp- $1^{-/-}(\mathrm{N}=8)$, non-cachectic control Parp- $2^{-/-}(\mathrm{N}=3)$, and LC-cachectic Parp-2 ${ }^{-/}(\mathrm{N}=5)$. Noncachectic control groups are represented in white bars, while LC-cachectic groups are represented in grey bars. Definition of abbreviations: LC, Lung cancer; PARP, poly-ADP ribose polymerase; OD, optical densities; a.u., arbitrary units. Statistical significance is represented as follows: *, $\mathrm{p} \leq 0.05$, ***, $\mathrm{p} \leq 0.001$, and n.s., non-significant differences between either wild type, Parp $-1^{-/-}$, or Parp- $2^{-/-}$ LC-cachectic mice and the corresponding non-cachectic control mice. Comparisons were assessed using ANOVA models that included genotype, cancer, and the interaction of both.

Fig. 5A-F Mean values and the corresponding 95\% confidence intervals of TRIM32 (panels A and B), MURF-1 (panels C and D), and atrogin-1 (panels E and F) protein content in the diaphragm and gastrocnemius as measured by optical densities in arbitrary units (OD, a.u.). For statistical analysis purposes, the following animals were used in each group: non-cachectic control wild type $(\mathrm{N}=7)$, LC-cachectic wild type $(\mathrm{N}=8)$, non-cachectic control Parp- $1^{-/-}(\mathrm{N}=7)$, LC-cachectic Parp- ${ }^{-/-}(\mathrm{N}=8)$, non-cachectic control Parp-2/- $(\mathrm{N}=3)$, and LC-cachectic Parp-2 ${ }^{-/-}(\mathrm{N}=5)$. Non-cachectic control groups are represented in white bars, while LC-cachectic groups are represented in grey bars. Definition of abbreviations: TRIM32, tripartite motif containing 32; MURF-1, muscle ring finger protein 1; LC, Lung cancer; PARP, poly-ADP ribose polymerase; OD, optical densities; a.u., arbitrary units. Statistical significance is represented as follows: ***, $p \leq 0.001$ and n.s., nonsignificant differences between either wild type, Parp $-1^{-/-}$, or Parp- $2^{-/-}$LC-cachectic mice and their respective control (non-tumor) mice. Comparisons were assessed using ANOVA models that included genotype, cancer, and the interaction of both.

Fig. 6A-D Mean values and the corresponding $95 \%$ confidence intervals of $\mathrm{p}-\mathrm{NF}-\kappa \mathrm{B}$ p $50 / \mathrm{NF}-\kappa \mathrm{B}$ p50 


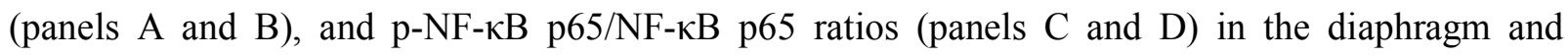
gastrocnemius, as measured by optical densities in arbitrary units (OD, a.u.). For statistical analysis purposes, the following animals were used in each group: non-cachectic control wild type $(\mathrm{N}=7)$, LC-cachectic wild type $(\mathrm{N}=8)$, non-cachectic control Parp- $1^{-/}(\mathrm{N}=7)$, LC-cachectic Parp- $1^{-/-}(\mathrm{N}=8)$, non-cachectic control Parp- $2^{-/-}(\mathrm{N}=3)$, and LC-cachectic Parp- $2^{-/-}(\mathrm{N}=5)$. Non-cachectic control groups are represented in white bars, while LC-cachectic groups are represented in grey bars. Definition of abbreviations: NF- $\kappa \mathrm{B}$ p50, nuclear factor- $\kappa \mathrm{B}$ p50 subunit; $\mathrm{p}-\mathrm{NF}-\kappa \mathrm{B}$ p50,

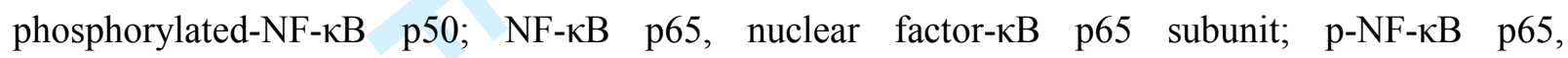
phosphorylated-NF- $\mathrm{B}$ p65; LC, Lung cancer; PARP, poly-ADP ribose polymerase; OD, optical densities; a.u., arbitrary units. Statistical significance is represented as follows: **, $\mathrm{p} \leq 0.01$, ***, $\mathrm{p} \leq 0.001$, and n.s., non-significant differences between either wild type, Parp- $1^{-/-}$, or Parp- $2^{-/-}$LCcachectic mice and their respective control (non-tumor) mice; $\uparrow \dagger \dagger, \mathrm{p} \leq 0.001$ between any of the control knockout animals and control (non-tumor) wild type mice. Comparisons were assessed using ANOVA models that included genotype, cancer, and the interaction of both.

Fig. 7A-H Mean values and the corresponding 95\% confidence intervals of p-Akt/Akt (panels A and B), p-mTOR/mTOR (panels C and D), and p-p70S6K/p70S6K (panels E and F) ratios are depicted in the diaphragm and gastrocnemius, as measured by optical densities in arbitrary units (OD, a.u.). For statistical analysis purposes, the following animals were used in each group: non-cachectic control wild type $(\mathrm{N}=7)$, LC-cachectic wild type $(\mathrm{N}=8)$, non-cachectic control Parp- ${ }^{-/-}(\mathrm{N}=7)$, LC-cachectic Parp- $1^{-/-}(\mathrm{N}=8)$, non-cachectic control Parp-2 $2^{-/-}(\mathrm{N}=3)$, and LC-cachectic Parp-2 ${ }^{-/-}(\mathrm{N}=5)$. Mean values and the corresponding $95 \%$ confidence intervals of the mitochondrial DNA copy number in the diaphragm (panel G) and gastrocnemius (panel $\mathrm{H}$ ), as measured by the mtDNA/mDNA ratio in arbitrary units (a.u.). For statistical analysis purposes, the following animals were used in each group: non-cachectic control wild type $(\mathrm{N}=8)$, LC-cachectic wild type $(\mathrm{N}=8)$, non-cachectic control Parp- $1^{-/-}(\mathrm{N}=8)$, LC-cachectic Parp- ${ }^{-/-}(\mathrm{N}=8)$, non-cachectic control Parp- $2^{-/-}(\mathrm{N}=6)$, and LC- 
cachectic Parp- $2^{-/-}(\mathrm{N}=6)$. Non-cachectic control groups are represented in white bars, while LCcachectic groups are represented in grey bars. Definition of abbreviations: Akt, RAC-alpha serine/threonine-protein kinase; p-Akt, phosphorylated-Akt; mTOR, mammalian target of rapamycin; p-mTOR, phosphorylated mTOR; p70S6K, p70 S6 kinase; p-70S6K, phosphorylated p70S6K; LC, Lung cancer; PARP, poly-ADP ribose polymerase; OD, optical densities; a.u., arbitrary units. Statistical significance is represented as follows: * $, p \leq 0.05, * *, p \leq 0.01$, ***, $p \leq 0.001$, and n.s., non-significant differences between either wild type, Parp- $1^{-/-}$, or Parp $-2^{-/-}$LC-cachectic mice and the corresponding non-cachectic control (non-tumor) mice; $\uparrow, p \leq 0.05$ between any of the non-cachectic control knockout animals and control (non-tumor) wild type mice. Comparisons were assessed using ANOVA models that included genotype, cancer, and the interaction of both.

Fig. 8A-D Mean values and the corresponding 95\% confidence intervals of MyHC (panels A anb B) and actin (panels $\mathrm{C}$ and $\mathrm{D}$ ) protein content in the diaphragm and gastrocnemius, as measured by optical densities in arbitrary units (OD, a.u.). For statistical analysis purposes, the following animals were used in each group: non-cachectic control wild type $(\mathrm{N}=7)$, LC-cachectic wild type $(\mathrm{N}=8)$, noncachectic control Parp-1 ${ }^{-/-}(\mathrm{N}=7)$, LC-cachectic Parp-1 ${ }^{-/-}(\mathrm{N}=8)$, non-cachectic control Parp-2 $2^{-/-}(\mathrm{N}=3)$, and LC-cachectic Parp- $2^{-/-}(\mathrm{N}=5)$. Non-cachectic control groups are represented in white bars, while LC-cachectic groups are represented in grey bars. Definition of abbreviations: MyHC, Myosin Heavy Chain; LC, Lung cancer; PARP, poly-ADP ribose polymerase; OD, optical densities; a.u., arbitrary units. Statistical significance is represented as follows: * $\mathrm{p} \leq 0.05, * *, \mathrm{p} \leq 0.01, * * *, \mathrm{p} \leq 0.001$, and n.s., non-significant differences between either wild type, Parp $-1^{-/-}$, or Parp- $2^{-/}$LC-cachectic mice and the corresponding non-cachectic control animals. Comparisons were assessed using

\section{ANOVA models that included genotype, cancer, and the interaction of both.}

John Wiley \& Sons, Inc. 
The description of the variables that demonstrated the reproducibition
Definition of abbreviations: Parp- $1^{-/-}$and Parp- $2^{-/-}$, poly-ADP rib
Statistical significance: $*, \mathrm{p} \leq 0.05, * *, \mathrm{p} \leq 0.01, * * *, \mathrm{p} \leq 0.001$,
cachectic mice and their respective control (non-tumor) rodents;
control (non-tumor) wild type mice. Comparisons were assessed
used to adjust for multiple comparisons among the study groups.

Definition of abbreviations: Parp- $1^{-/-}$and Parp- $2^{-/-}$, poly-ADP ribose polymerase-1, and -2 knockout mice, LC, lung cancer; N.A., not applicable.

Statistical significance: $*, \mathrm{p} \leq 0.05, * *, \mathrm{p} \leq 0.01$, ***, $\mathrm{p} \leq 0.001$, and n.s., non-significant differences between either wild type, Parp- $1^{-/-}$, or Parp- $2^{-/-}$LCcachectic mice and their respective control (non-tumor) rodents; $\uparrow, p \leq 0.05, \dagger \dagger, p \leq 0.01$, and $\uparrow \dagger \uparrow, p \leq 0.001$ between any of the control knockout animals and control (non-tumor) wild type mice. Comparisons were assessed using one-way analysis of variance (ANOVA), in which Dunnett's post hoc analysis was

Cancer-induced cachexia in Parp-1 and -2 deficient mice Table 1. Validation of the experimental model: physiological characteristics of wild type, Parp- ${ }^{-/}$, and Parp- $2^{-/}$mice at the end of the study period

\begin{tabular}{|c|c|c|c|c|c|c|}
\hline & \multicolumn{2}{|c|}{ Wild type mice } & \multicolumn{2}{|c|}{ Parp- ${ }^{-/-}$mice } & \multicolumn{2}{|c|}{ Parp- $2^{-/-}$mice } \\
\hline & $\begin{array}{l}\text { Control } \\
(\mathrm{N}=12)\end{array}$ & $\begin{array}{l}\text { LC-cachexia } \\
(\mathrm{N}=14)\end{array}$ & $\begin{array}{c}\text { Control } \\
(\mathrm{N}=8)\end{array}$ & $\begin{array}{l}\text { LC-cachexia } \\
(\mathrm{N}=12)\end{array}$ & $\begin{array}{c}\text { Control } \\
(\mathrm{N}=6)\end{array}$ & $\begin{array}{l}\text { LC-cachexia } \\
(\mathrm{N}=6)\end{array}$ \\
\hline Age at baseline (weeks) & 10 & 10, n.s. & 10 & 10, n.s. & 10 & 10 , n.s. \\
\hline Subcutaneous tumor weight $(\mathrm{g})$ & & $1.86(0.6)$ & & $1.11(0.3), * *$ & & $1.21(0.35), *$ \\
\hline Body weight at baseline (g) & $19.57(0.85)$ & $19.52(0.80)$, n.s. & $19.28(0.78)$ & $18.61(0.93)$, n.s. & $19.25(1.06)$ & 19.89 (0.92), n.s. \\
\hline Body weight gain (\%) & $+9.26(2.63)$ & $-5.39(9.54), * * *$ & $+6.96(2.23)$ & $+1.55(3.69), *$ & $+4.34(2.87)$ & $+3.06(6.81)$, n.s. \\
\hline Diaphragm weight (g) & $0.090(0.01)$ & $0.067(0.011), * * *$ & $0.073(0.01), \dagger$ & $0.062(0.007), *$ & $0.076(0.012), \dagger$ & $0.086(0.013)$, n.s. \\
\hline Gastrocnemius weight $(\mathrm{g})$ & $0.118(0.006)$ & $0.080(0.018), * * *$ & $0.105(0.003), \dagger$ & $0.096(0.007), *$ & $0.096(0.012), \uparrow \dagger \dagger$ & 0.098 (0.012), n.s. \\
\hline Limb strength gain (\%) & $+9.48(6.47)$ & $-12.50(10.52), * * *$ & $+12.86(8.13)$ & $-0.45(6.08), * *$ & $+3.33(1.99)$ & $+2.10(5.40)$, n.s. \\
\hline
\end{tabular}


Cancer-induced cachexia in Parp-1 and -2 deficient mice Table 2. Muscle phenotypic features in wild type, Parp- $1^{-/-}$, and Parp- $2^{-/-}$mice at the end of the study period

\begin{tabular}{|c|c|c|c|c|c|c|c|}
\hline & \multicolumn{3}{|c|}{ Wild type mice } & \multicolumn{2}{|c|}{ Parp- $1^{-/-}$mice } & \multicolumn{2}{|c|}{ Parp- $2^{-/-}$mice } \\
\hline & Muscle & $\begin{array}{l}\text { Control } \\
(\mathrm{N}=10)\end{array}$ & $\begin{array}{l}\text { LC-cachexia } \\
\qquad(\mathrm{N}=10)\end{array}$ & $\begin{array}{l}\text { Control } \\
(\mathrm{N}=8)\end{array}$ & $\begin{array}{l}\text { LC-cachexia } \\
\qquad(\mathrm{N}=12)\end{array}$ & $\begin{array}{l}\text { Control } \\
(\mathrm{N}=6)\end{array}$ & $\begin{array}{l}\text { LC-cachexia } \\
\qquad(\mathrm{N}=6)\end{array}$ \\
\hline \multicolumn{8}{|c|}{ Fiber type composition } \\
\hline Type I fibers (\%) & $\begin{array}{l}\text { Diaphragm } \\
\text { Gastrocnemius }\end{array}$ & $\begin{array}{l}9(2) \\
13(3)\end{array}$ & $\begin{array}{l}8(3), \text { n.s. } \\
13(3), \text { n.s. }\end{array}$ & $\begin{array}{l}9(1) \\
13(2)\end{array}$ & $\begin{array}{l}9(2), \text { n.s. } \\
13(2), \text { n.s. }\end{array}$ & $\begin{array}{c}7(2) \\
17(4)\end{array}$ & $\begin{array}{l}9(2), \text { n.s. } \\
15(2), \text { n.s. }\end{array}$ \\
\hline $\begin{array}{l}\text { Type II fibers } \\
(\%)\end{array}$ & $\begin{array}{l}\text { Diaphragm } \\
\text { Gastrocnemius }\end{array}$ & $\begin{array}{l}91(2) \\
87(3)\end{array}$ & $\begin{array}{l}92(3), \text { n.s. } \\
87 \text { (3), n.s. }\end{array}$ & $\begin{array}{l}91(1) \\
87(2)\end{array}$ & $\begin{array}{l}91 \text { (2), n.s. } \\
87(2), \text { n.s. }\end{array}$ & $\begin{array}{l}92(3) \\
83(4)\end{array}$ & $\begin{array}{l}90 \text { (2), n.s. } \\
85 \text { (2), n.s. }\end{array}$ \\
\hline $\begin{array}{l}\text { Type I fibers area } \\
\left(\mu \mathrm{m}^{2}\right)\end{array}$ & $\begin{array}{l}\text { Diaphragm } \\
\text { Gastrocnemius }\end{array}$ & $\begin{array}{l}322(70) \\
965(107)\end{array}$ & $\begin{array}{c}239(28), * * \\
673(121), * * *\end{array}$ & $\begin{array}{c}325(77) \\
864(109)\end{array}$ & $\begin{array}{c}289(58), \text { n.s. } \\
730(190), \text { n.s. }\end{array}$ & $\begin{array}{c}292(49) \\
775(128), \dagger\end{array}$ & $\begin{array}{l}311 \text { (67), n.s. } \\
707 \text { (82), n.s. }\end{array}$ \\
\hline $\begin{array}{l}\text { Type II fibers } \\
\text { area }\left(\mu \mathrm{m}^{2}\right)\end{array}$ & $\begin{array}{l}\text { Diaphragm } \\
\text { Gastrocnemius }\end{array}$ & $\begin{array}{c}397(78) \\
924(134)\end{array}$ & $\begin{array}{c}310(58), * \\
714(135), * *\end{array}$ & $\begin{array}{l}384(80) \\
885(99)\end{array}$ & $\begin{array}{l}371 \text { (76), n.s. } \\
743 \text { (182), n.s. }\end{array}$ & $\begin{array}{l}344(98) \\
804(66)\end{array}$ & $\begin{array}{c}395 \text { (114), n.s. } \\
714 \text { (61), n.s. }\end{array}$ \\
\hline \multicolumn{8}{|c|}{ Muscle abnormalities } \\
\hline $\begin{array}{l}\text { Abnormal } \\
\text { fraction }(\%)\end{array}$ & $\begin{array}{l}\text { Diaphragm } \\
\text { Gastrocnemius }\end{array}$ & $\begin{array}{l}8.8(0.7) \\
3.7(1.6)\end{array}$ & $\begin{array}{l}14.3(3.9), * * \\
7.9(1.7), * * *\end{array}$ & $\begin{array}{c}9.7(2.3) \\
4.4(1)\end{array}$ & $\begin{array}{c}16.1(4.9), * * * \\
7.4(2.1), * *\end{array}$ & $\begin{array}{l}11.5(2.6) \\
5.0(1.8)\end{array}$ & $\begin{array}{l}16(2.5),{ }^{*} \\
8.0(2.4),{ }^{*}\end{array}$ \\
\hline $\begin{array}{l}\text { Inflammatory } \\
\text { cells }(\%)\end{array}$ & $\begin{array}{l}\text { Diaphragm } \\
\text { Gastrocnemius }\end{array}$ & $\begin{array}{l}3.9(0.4) \\
2.1(1.0)\end{array}$ & $\begin{array}{l}6.3(1.4), * * \\
5.3(1.8), * * *\end{array}$ & $\begin{array}{c}6(1.2), p=0.055 \\
2.6(0.6)\end{array}$ & $\begin{array}{c}9.7(2.6), * * * \\
4.4(1.6), *\end{array}$ & $\begin{array}{c}6.6(1.5), \dagger \dagger \\
2.3(1.1)\end{array}$ & $\begin{array}{l}9.7(0.8), * * \\
4.6(1.8), *\end{array}$ \\
\hline $\begin{array}{l}\text { Internal nuclei } \\
(\%)\end{array}$ & $\begin{array}{l}\text { Diaphragm } \\
\text { Gastrocnemius }\end{array}$ & $\begin{array}{l}3.7(1.0) \\
1.5(0.7)\end{array}$ & $\begin{array}{l}7.2(3.7), * * \\
2.3(0.8), *\end{array}$ & $\begin{array}{l}3.3(1.5) \\
1.7(0.8)\end{array}$ & $\begin{array}{l}5.5(2.2), * \\
2.8(0.8), * *\end{array}$ & $\begin{array}{l}4.3(0.7) \\
2.2(0.5)\end{array}$ & $\begin{array}{l}5.4(0.6), * \\
2.8(0.4), *\end{array}$ \\
\hline $\begin{array}{l}\text { TUNEL - } \\
\text { positive nuclei } \\
(\%)\end{array}$ & $\begin{array}{l}\text { Diaphragm } \\
\text { Gastrocnemius }\end{array}$ & $\begin{array}{l}48.5(6.7) \\
51.6(5.7)\end{array}$ & $\begin{array}{l}65.8(5.9), * * * \\
67.7(3.8), * * *\end{array}$ & $\begin{array}{c}49.1(2.5) \\
49(0.7)\end{array}$ & $\begin{array}{l}57.5(1.8), * * * \\
59.5(2.6), * * *\end{array}$ & $\begin{array}{c}49(1.8) \\
48.6(1.7)\end{array}$ & $\begin{array}{l}59.5(1.7), * * * \\
60.8(2.4), * * *\end{array}$ \\
\hline
\end{tabular}

\section{The description of the variables that demonstrated the reproducibility of the animal model is presented as mean (standard deviation).}

Definition of abbreviations: Parp- $1^{-/-}$and Parp- $2^{-/-}$, poly-ADP ribose polymerase-1, and -2 knockout mice; LC, lung cancer; $\mu \mathrm{m}$, micrometer; n.s., non-significant.

Statistical significance: $*, \mathrm{p} \leq 0.05,{ }^{* *}, \mathrm{p} \leq 0.01, * * *, \mathrm{p} \leq 0.001$, and n.s., non-significant differences between either wild type, Parp- $1^{-/-}$or Parp- $2^{-/-}$LCcachectic mice and their respective control (non-tumor) rodents; $\dagger, \mathrm{p} \leq 0.05$, and $\dagger \dagger, \mathrm{p} \leq 0.01$ between any of the control knockout animals and control (non-tumor) wild type mice. Comparisons were assessed using one-way analysis of variance (ANOVA), in which Dunnett's post hoc analysis was used to adjust for multiple comparisons among the study groups. 
A. Chacon-Cabrera et al. Fig. 1

A

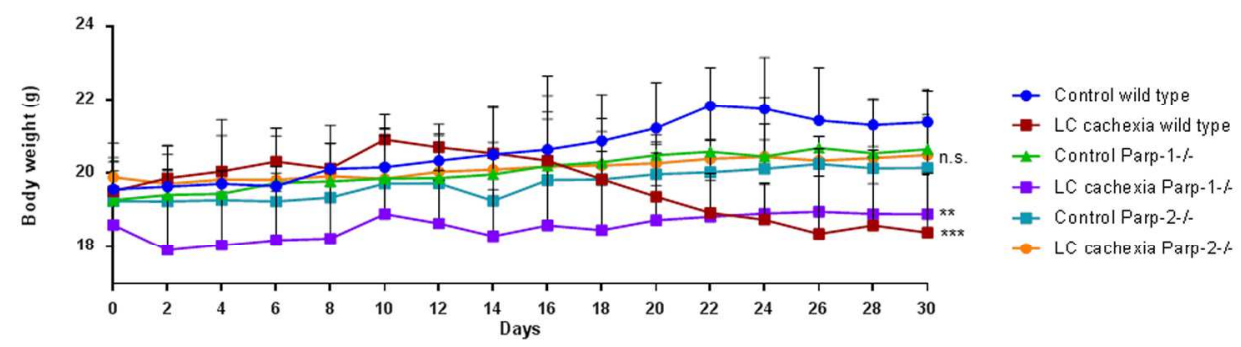

Figure $1 \mathrm{~A}$

$254 \times 190 \mathrm{~mm}(300 \times 300$ DPI)

John Wiley \& Sons, Inc. 


1
2
3
4
5
6
7
8
9
10
11
12
13
14
15
16
17
18
19
20
21
22
23
24
25
26
27
28
29
30
31
32
33
34
35
36
37
38
39
40
41
42
43
44
45
46
47
48
49
50
51
52
53
54
55
56
57
58
60

A. Chacon-Cabrera et al. Fig. 1

B

Diaphragm

c

Gastrocnemius
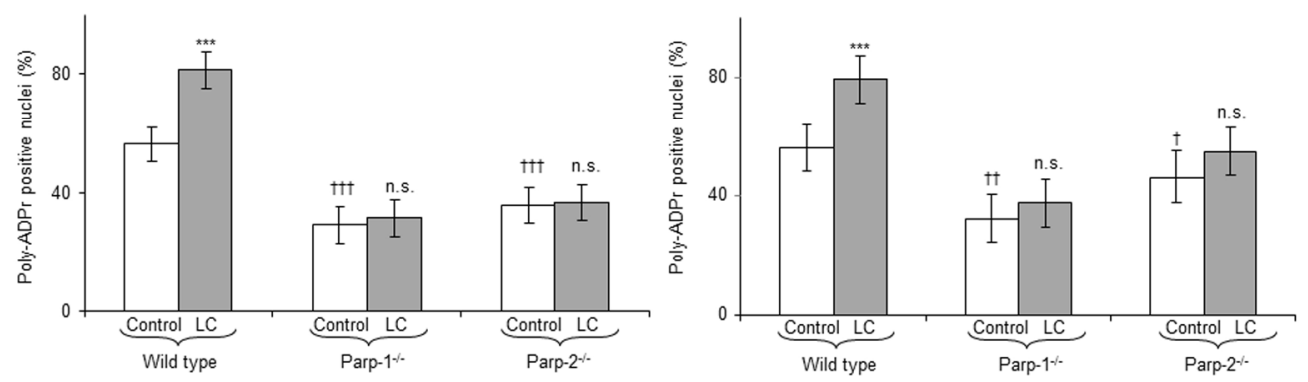

Figure 1B-1C

$254 \times 190 \mathrm{~mm}(300 \times 300$ DPI)

John Wiley \& Sons, Inc. 
A. Chacon-Cabrera et al. Fig. 2
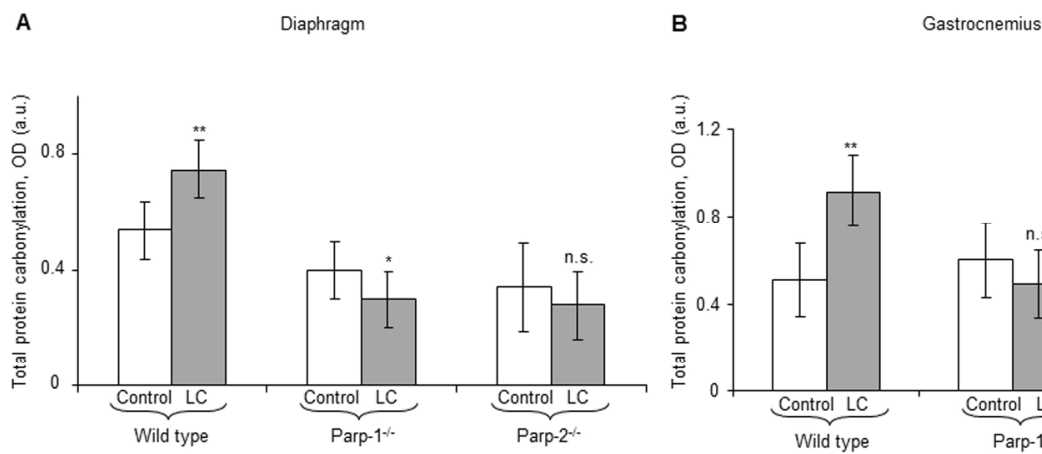

10

11

12

C

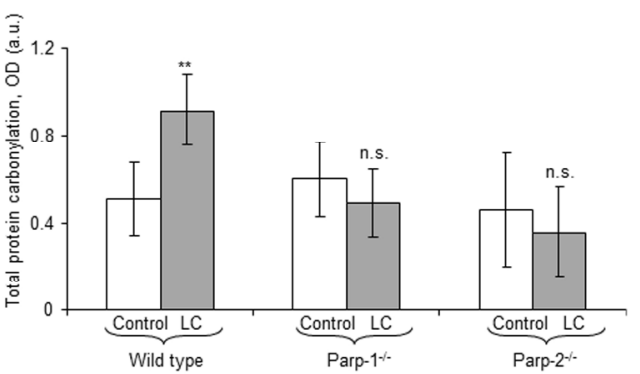

D
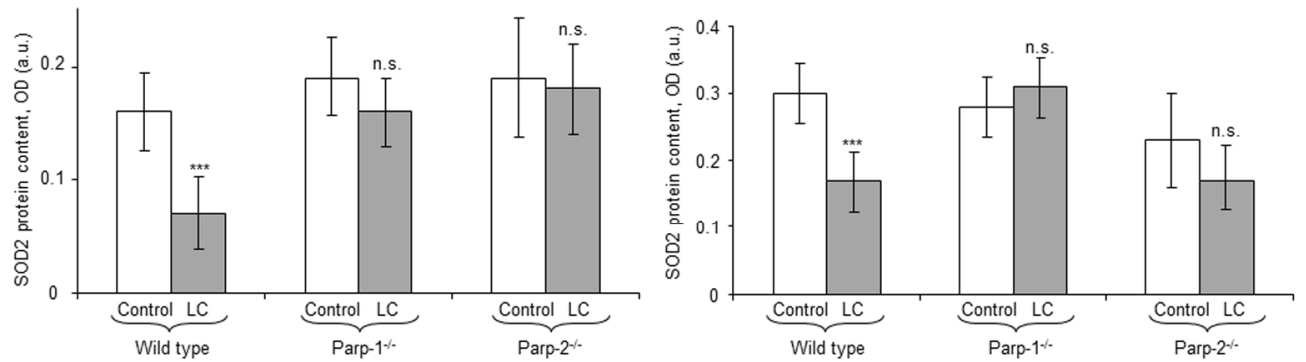

Figure 2A-2D

$254 \times 190 \mathrm{~mm}(300 \times 300$ DPI $)$

35

36

37

38

39

40

41

42

43

44

45

46

47

48

49

50

51

52

53

54

55

56

57

58

59

60

John Wiley \& Sons, Inc. 

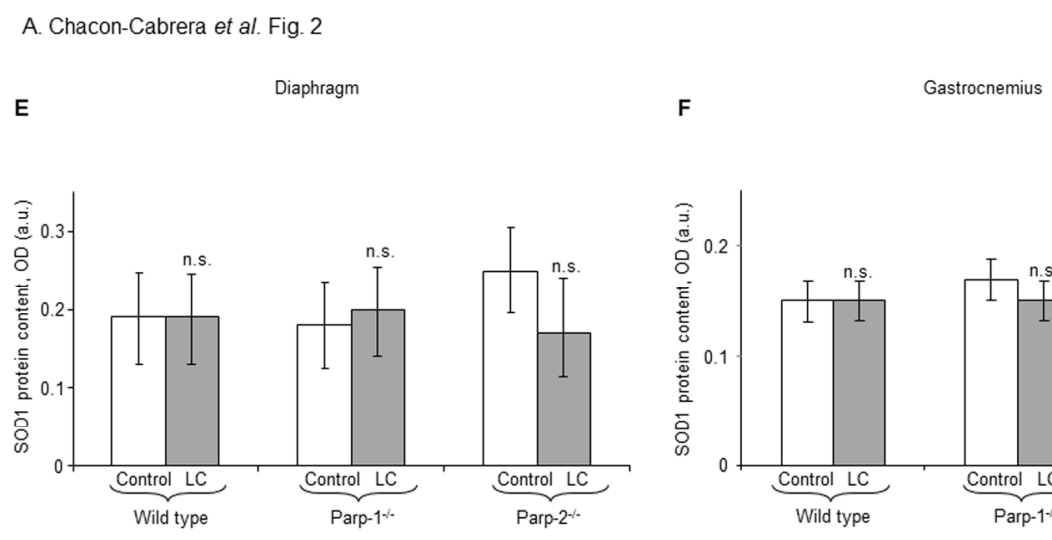

10 
A. Chacon-Cabrera et al. Fig. 3

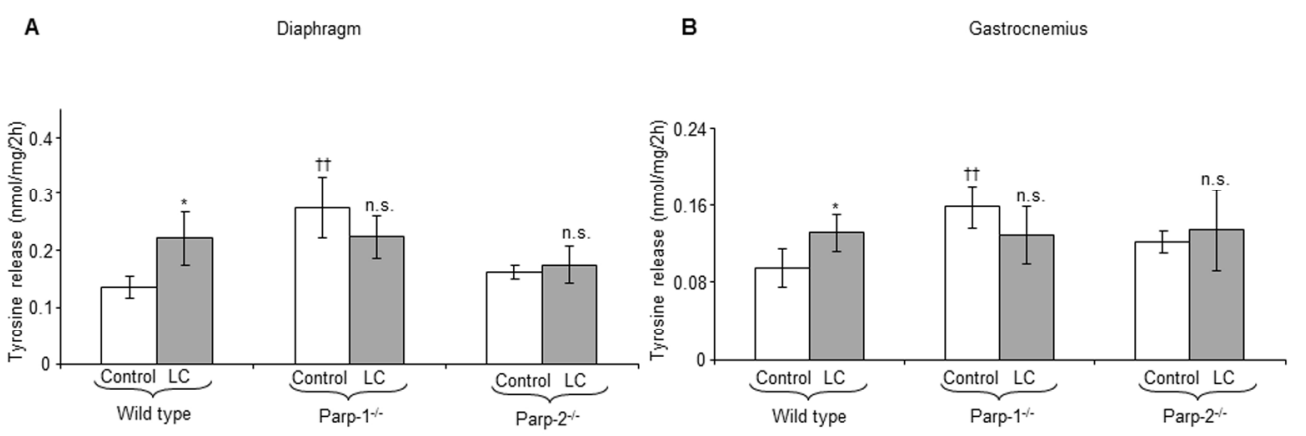

Figure 3A-3B

$254 \times 190 \mathrm{~mm}(300 \times 300$ DPI)

John Wiley \& Sons, Inc. 
A. Chacon-Cabrera et al. Fig. 4
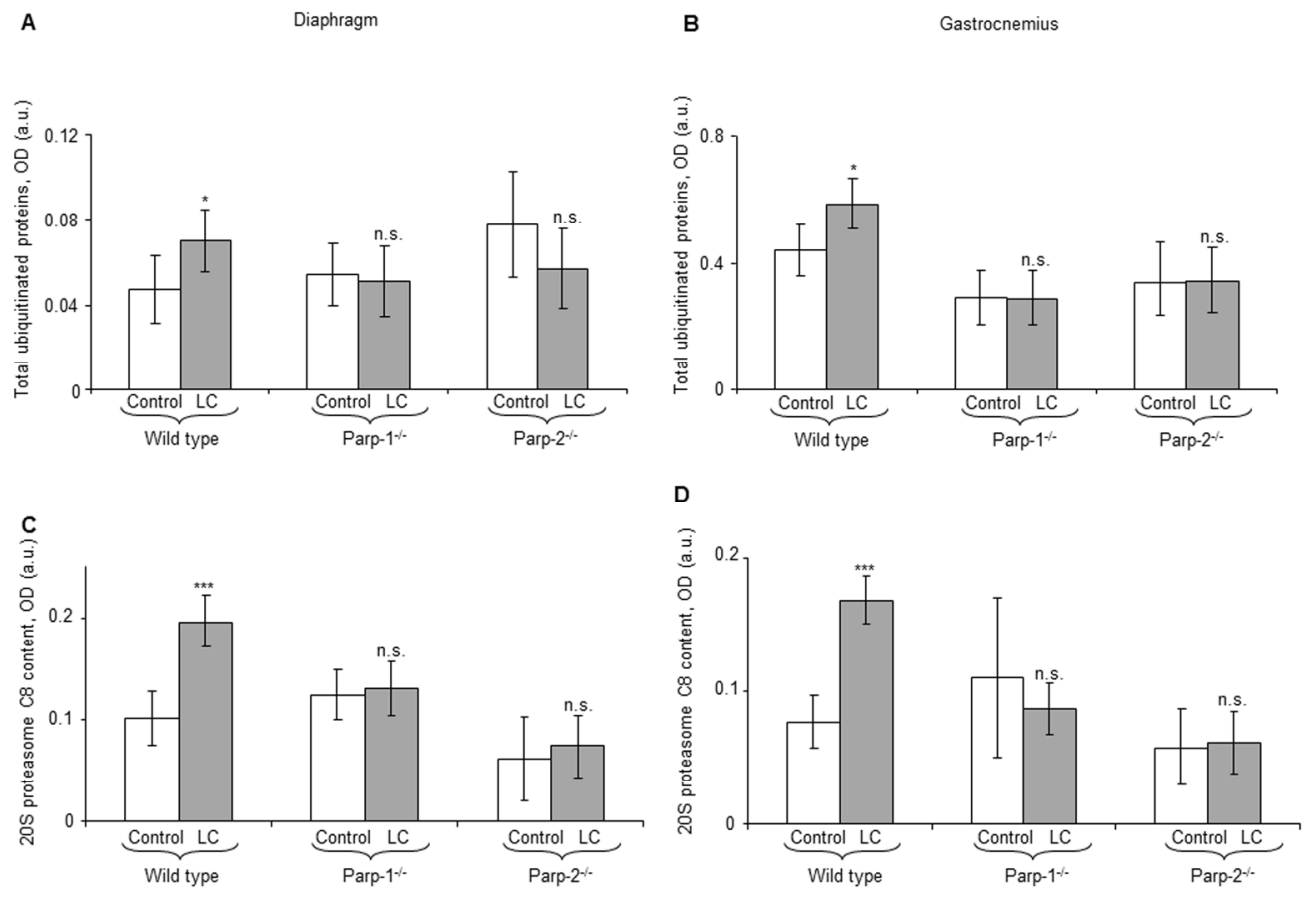

Figure 4A-4D

$254 \times 190 \mathrm{~mm}(300 \times 300$ DPI $)$

John Wiley \& Sons, Inc. 
A. Chacon-Cabrera et al. Fig. 5

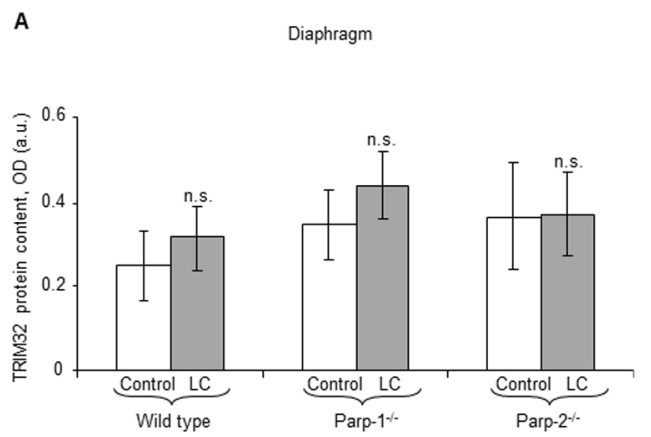

B

Gastrocnemius

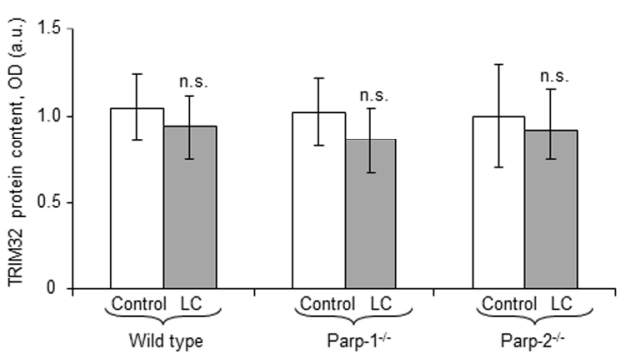

C

D
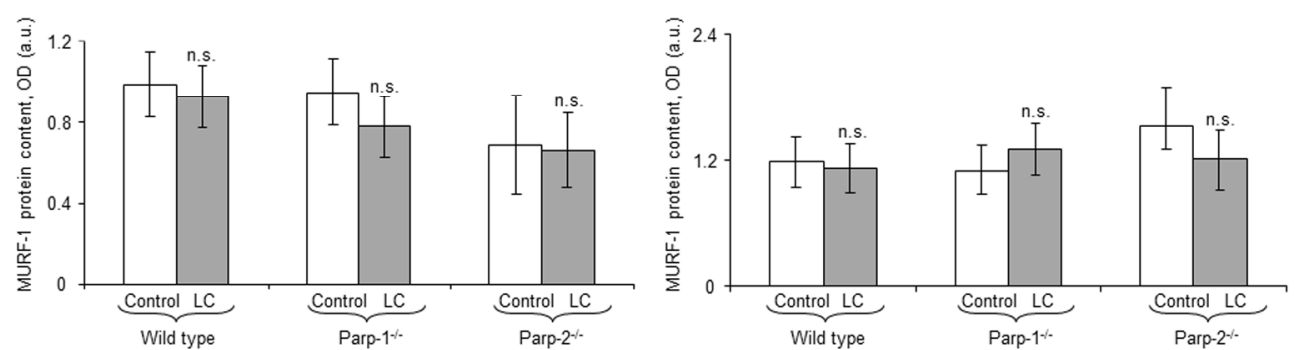

Figure 5A-5D

$254 \times 190 \mathrm{~mm}(300 \times 300 \mathrm{DPI})$

John Wiley \& Sons, Inc. 
A. Chacon-Cabrera et al. Fig. 5
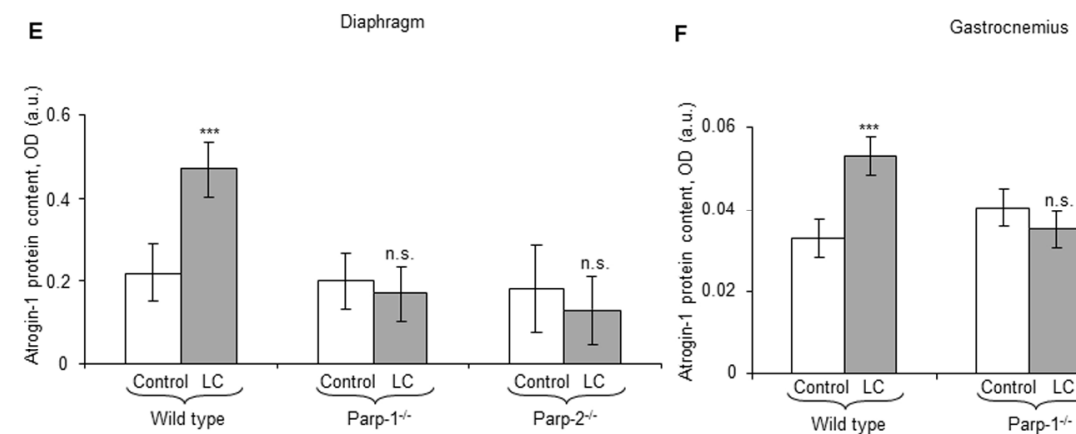

0

21 
A. Chacon-Cabrera et al. Fig. 6
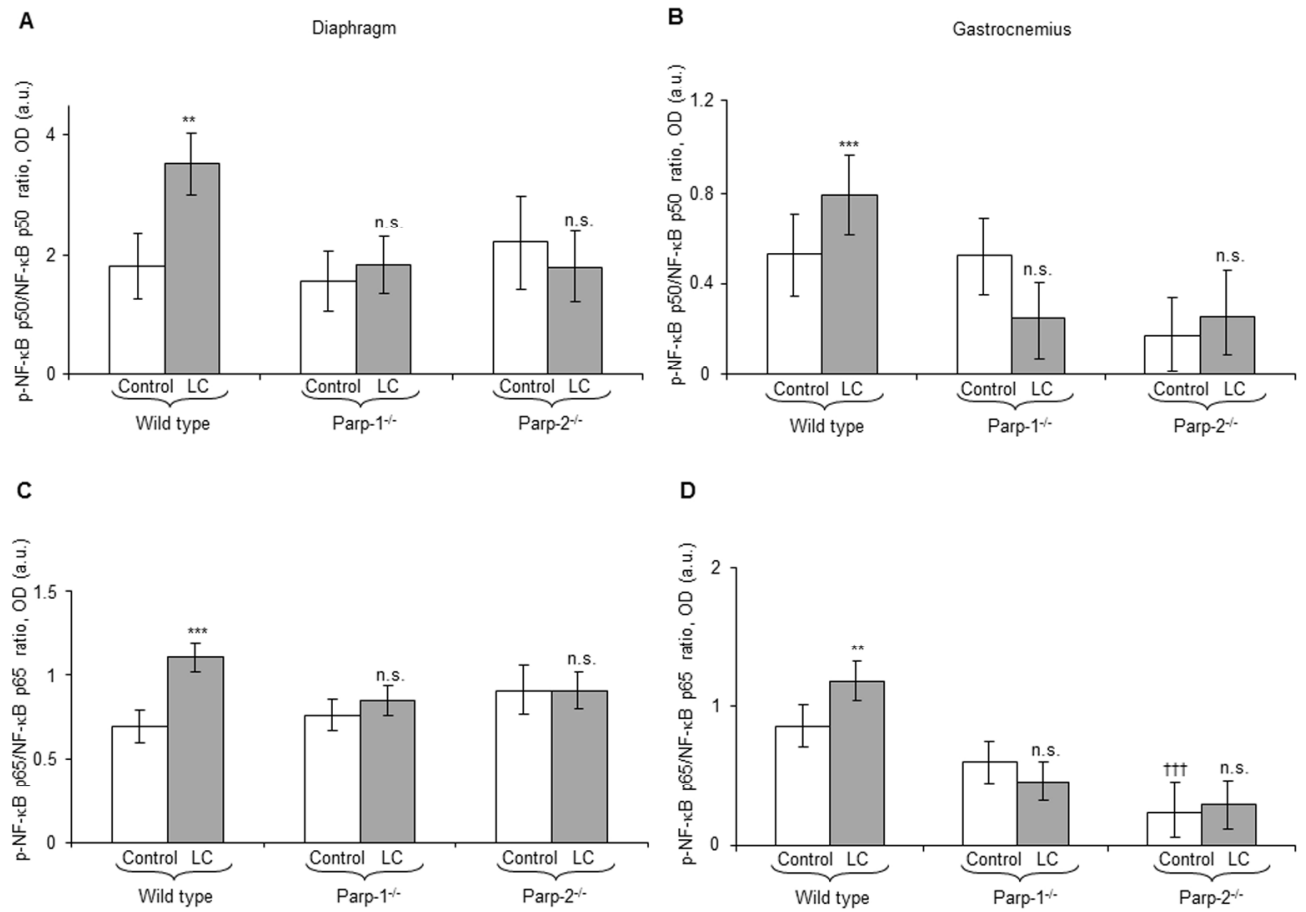

D

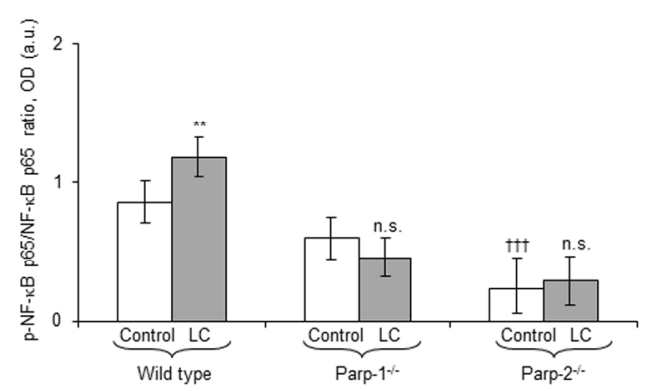

Figure 6A-6D

$254 \times 190 \mathrm{~mm}(300 \times 300 \mathrm{DPI})$

John Wiley \& Sons, Inc. 
A. Chacon-Cabrera et al. Fig. 7
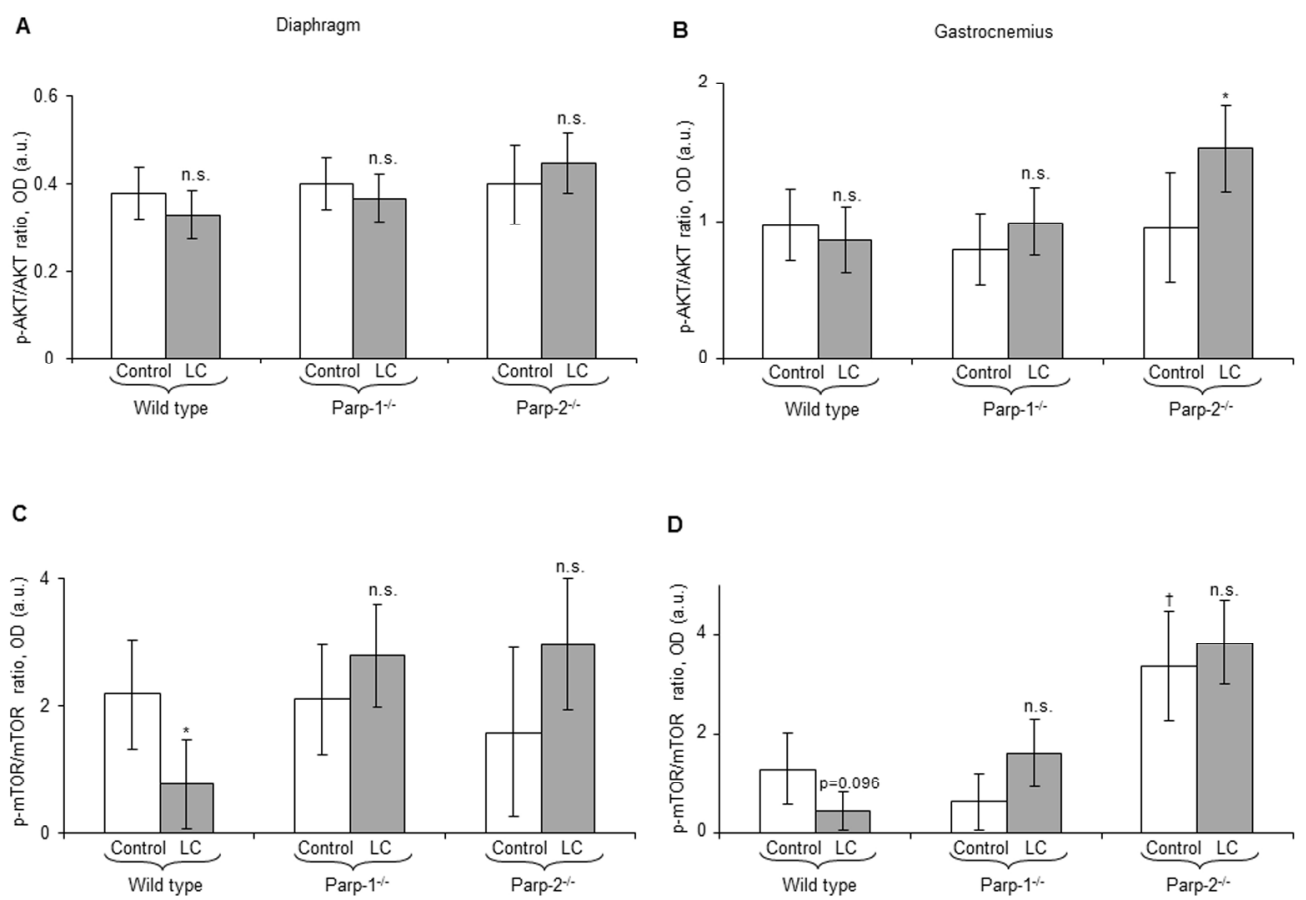

D

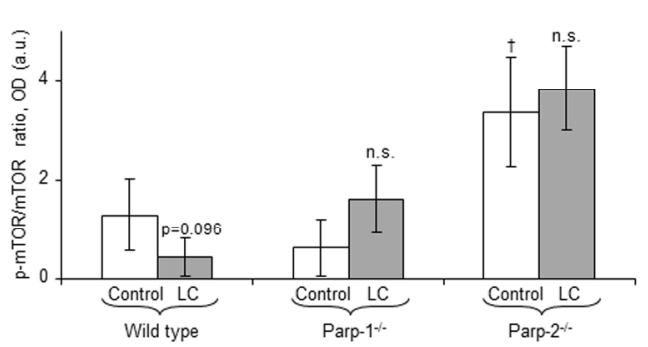

Figure 7A-7D

$254 \times 190 \mathrm{~mm}(300 \times 300$ DPI $)$

John Wiley \& Sons, Inc. 

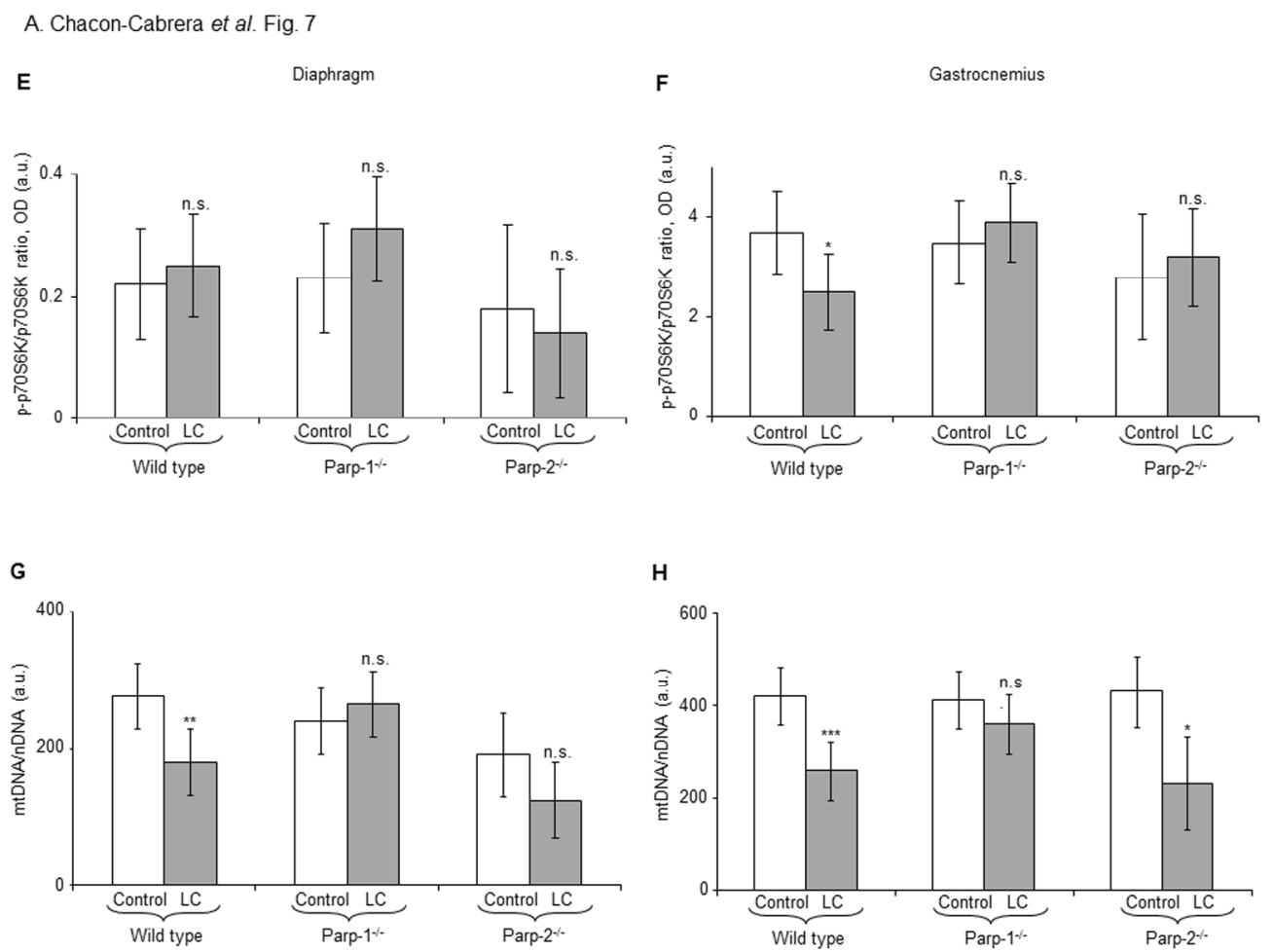

Figure 7E-7H

$254 \times 190 \mathrm{~mm}(300 \times 300$ DPI $)$

John Wiley \& Sons, Inc. 
A. Chacon-Cabrera et al. Fig. 8

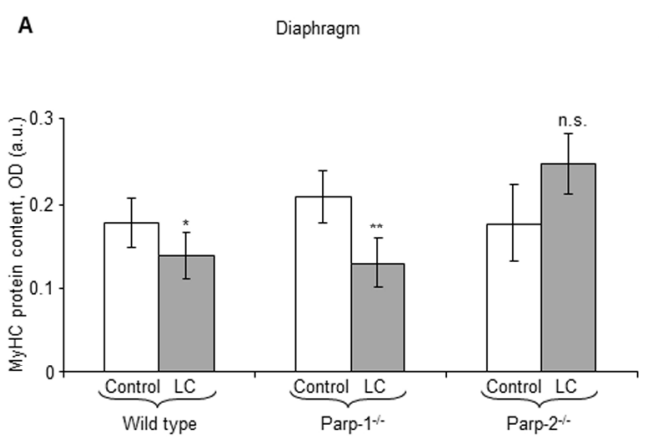

B Gastrocnemius

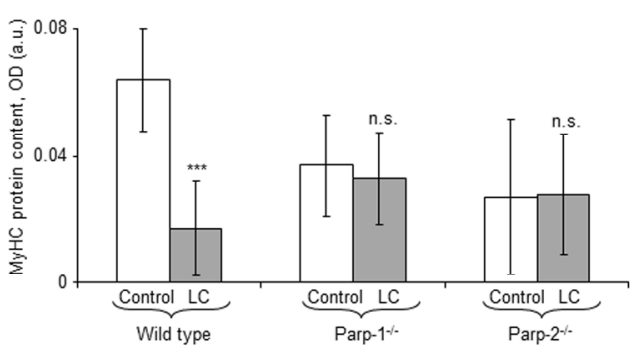

c

D
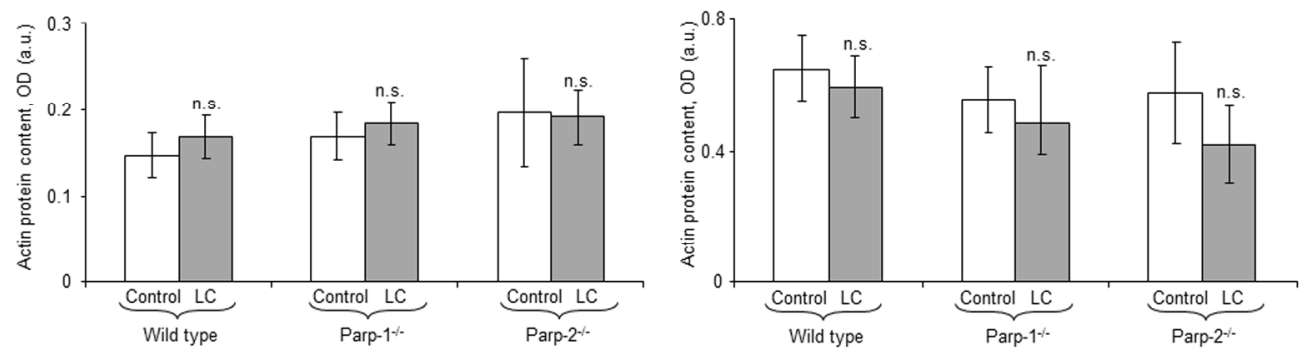

Figure $8 \mathrm{~A}-8 \mathrm{D}$

$254 \times 190 \mathrm{~mm}(300 \times 300$ DPI $)$

35

36

37

38

39

40

41

42

43

44

45

46

47

48

49

50

51

52

53

54

55

56

57

58

59

60

John Wiley \& Sons, Inc. 